\title{
Electromagnetic interference shielding performance of carbon nanostructure reinforced, 3D printed polymer composites
}

\author{
Pawan Verma ${ }^{2,3}$, Taruna Bansala ${ }^{3}$, Sampat Singh Chauhan ${ }^{4}$, Devendra Kumar ${ }^{4}$, \\ Suleyman Deveci ${ }^{5}$, and S. Kumar ${ }^{1,2, \star}$ (i) \\ ${ }^{7}$ James Watt School of Engineering, University of Glasgow, Glasgow G12 8QQ, UK \\ ${ }^{2}$ Department of Mechanical Engineering, Khalifa University, P.O. Box 127788, Abu Dhabi, United Arab Emirates \\ ${ }^{3}$ Department of Chemical Engineering, Texas A\&M University, College Station, TX 77840, USA \\ ${ }^{4}$ Department of Material Science and Engineering, Indian Institute of Technology, New Delhi 110016, India \\ ${ }^{5}$ Borouge Pvt. Ltd, Abu Dhabi, United Arab Emirates
}

Received: 12 November 2020

Accepted: 2 March 2021

Published online:

7 April 2021

(C) The Author(s) 2021

\begin{abstract}
We report the electrical, mechanical and electromagnetic interference (EMI) shielding performance of polypropylene random copolymer (PPR)/multi-wall carbon nanotube (MWCNT) nanocomposites enabled via customized fused filament fabrication process. The electro-conductive PPR/MWCNT filament feedstocks were fabricated via shear-induced melt-blending process that allows 3D printing of nanoengineered composites even at higher MWCNT loading (up to $8 \mathrm{wt} \%$ ). The uniform dispersion of MWCNTs in PPR matrix confirmed via Raman spectroscopy and scanning electron microscopy facilitates better mechanical, electrical and EMI shielding performance. The results furthermore show enhanced shielding properties and higher attenuation for the nanocomposites printed in $90^{\circ}$ direction $(\sim-37 \mathrm{~dB}$ for $8 \mathrm{wt} \%$ MWCNT loading). Effective interfacial adhesion between the beads with lesser extent of voids (confirmed via micro-computed tomography) endorsed low transmission loss in nanocomposites printed in $90^{\circ}$ direction compared to samples printed in $0^{\circ}$ direction. Surface architected structure (frustum shape) reveals higher specific shielding effectiveness (maximum $\sim-40 \mathrm{dBg}^{-1} \mathrm{~cm}^{3},+38 \%$ ) over the plain structure. The realization of excellent shielding effectiveness $(\sim 99.9 \%$ attenuation) of additive manufacturing-enabled PPR/MWCNT nanocomposites demonstrates their potential for lightweight and strong EMI shields.
\end{abstract}

Handling Editor: Joshua Tong.

Address correspondence to E-mail: s.kumar@eng.oxon.org

https:/ / doi.org/10.1007/s10853-021-05985-0 


\section{GRAPHICAL ABSTRACT}

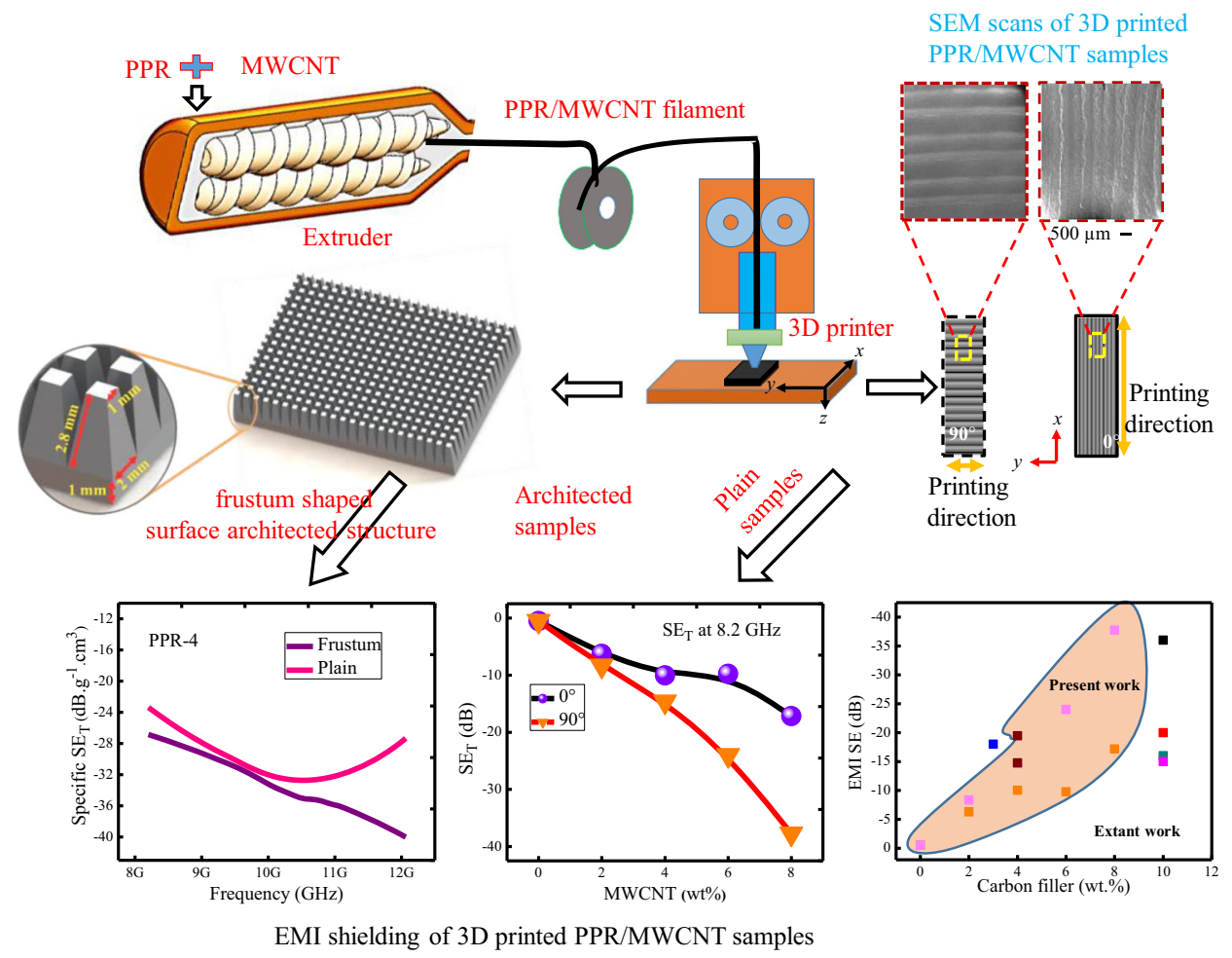

\section{Introduction}

The research advances in electronics and communication industries have led to increasing usage of electronic gadgets, causing electronic pollution mainly in the form of radiated electromagnetic (EM) energy, known as electromagnetic interference (EMI) [1]. These EM waves can interfere, interrupt, degrade, and/or impede the efficient operation of nearby electronic devices and badly affect human health and other living organisms [2]. Therefore, numerous attempts have been made to suppress the EM radiation by using EMI shielding materials [3-7]. Electroconductive polymer nanocomposites are considered as an effective shielding material for EMI shielding applications since they exhibit advantages such as corrosion resistance, lightness and low processing cost over commercially available metal-based EMI shields [8-10]. The shielding effectiveness (SE) through EMI shield can be realized by degrading the effect of incident EM rays via absorption and refection. The mobile charge carriers like holes or electrons are responsible for reflection loss while the magnetic/dielectric polarization and associated losses contribute to absorption loss [11]. The absorption loss also exclusively depends on the multiple internal reflection (MIR) within the shielding material. The internal architecture and morphology (surface and bulk) can also influence the EMI shielding response of materials [12].

Additive manufacturing (AM) (aka 3D printing (3DP))-enabled materials development is gaining greater attention due to the design freedom it offers [13-17]. 3DP enables the realization of complex structures [18-21]. Furthermore, among all the available AM technologies, fused deposition modeling (FDM) is more attractive due to its operational simplicity, high reliability and low-cost [22-25]. Although numerous reports exist on EMI shielding behavior of polymer composites, only a few studies have explored the EMI shielding performance of $3 \mathrm{D}$ 
printed polymer composites. For example, Viskadourakis et al. [12] used 3D printed polylactic acid (PLA)/graphene composites with pyramid shape surface features and observed a SE of $\sim-22 \mathrm{~dB}$ over plain samples in the frequency range of 3.5-7 GHz (C-band). Likewise, Paddubskaya et al. [26] reported EMI measurements of sandwich structures containing two nanocarbon layers and achieved EMI SE in the range of $8-15 \mathrm{~dB}$ in low-frequency range (from $20 \mathrm{~Hz}$ to $2 \mathrm{MHz}$ ). Chizari et al. [27] used PLA/carbon nanotube (CNT)-based conducting ink to print semi-transparent scaffolds and bulk samples and reported SE values of $\sim 30 \mathrm{~dB}$ and $\sim 55 \mathrm{~dB}$ with $30 \mathrm{wt} \%$ CNT loading for the bulk and scaffold structures, respectively. Schmitz et al. [28] developed 3D printable acrylonitrile butadiene styrene (ABS) composite filament loaded with $\mathrm{CNT}$ and carbon black $(\mathrm{CB})$, through the melt-blending process. These samples showed a SE of $\sim 18 \mathrm{~dB}$ at $3 \mathrm{wt} \%$ filler loading (CNT/CB: 50/50) in perpendicular concentric direction. Similarly, Prashantha et al. [29] reported an EMI SE of $\sim 16 \mathrm{~dB}$ for PLA/Graphene composites at $10 \mathrm{wt} \%$ loading. Spinelli et al. [30, 31] investigated the EMI shielding performance of $3 \mathrm{D}$ printed nanocarbon/PLA composites and reported the best EMI shielding effectiveness of $92 \%$ for the composites comprising $4.5 \mathrm{wt} \%$ GNP and $1.5 \mathrm{wt} \%$ MWCNT in GHz range frequency while they exhibited $96 \%$ EMI shielding effectiveness for the composites comprising $3 \mathrm{wt} \%$ GNP and $3 \mathrm{wt} \%$ MWCNT in $\mathrm{THz}$ frequency range.

Despite demonstrating acceptable level of shielding performance $(-20 \mathrm{~dB})$ at higher filler loading, other metrics such as the mechanical properties (particularly strength) and economic viability (lowcost raw material, energy-savings and process economy), have not been considered in most of the aforementioned studies. At high filler loading, desirable EMI properties emerge while the mechanical properties degrade due to phase separation and filler agglomeration [32]. Furthermore, most studies explored the EMI shielding performance (of samples enabled via 3D printing) of PLA based composites as PLA is easily processable via FDM 3D printing. Moreover, at higher filler loading, the mechanical properties of PLA substantially degrade. In contrast, the commodity polymers such as polypropylene (PP), polypropylene random copolymer (PPR), high density polyethylene (HDPE) etc. offer good mechanical properties even at high loading but 3D printing of these polymers is challenging as they suffer from FDM 3D printing related issues such as shrinkage, warpage etc. [33, 34]

To enable 3D printed composites with multifunctional attributes for high-end applications, electromagnetic and radiation shielding properties must be introduced to structures without compromising their mechanical strength while retaining the commercial viability aspects such as low-cost and ease of processing. Therefore, a consolidated study focused on the fabrication and 3D printing of low-cost, lightweight polymer composites that can exhibit appreciable electrical, mechanical and EMI performance is still missing and is indispensable. This study, therefore, is focused on the development of $3 \mathrm{D}$ printable polypropylene random copolymer (PPR)/multiwalled carbon nanotubes (MWCNT) filament feedstocks with high filler loading (up to $8 \mathrm{wt} \%$ ) via high shear-induced melt-blending technique using twinscrew extruder. Furthermore, PPR/MWCNT nanocomposites samples were fabricated via customized fused filament fabrication technique, overcoming the problems associated with 3D printing of PPR, in two different print directions i.e., $0^{\circ}$ and $90^{\circ}$ and their EMI shielding, mechanical and electrical properties were analyzed. Surface tailored structures (with frustum shape surface features) was also fabricated and the shielding response of surface architected PPR/MWCNT nanocomposites was assessed relative to non-tailored samples. The dispersion-state of MWCNT in PPR matrix was examined via Raman spectroscopy and scanning electron microscopy. In addition, the internal morphology of the nanocomposites was analyzed by micro-computed tomography $(\mu \mathrm{CT})$. The choice of polymer matrix (PPR), filler material (MWCNT), filament fabrication technique (melt blending) and 3D printing (FFF) method were highlighted to validate the commercial viability and practical utility of PPR/MWCNT nanocomposites for EMI shielding applications.

\section{Materials and experimental methods}

\section{Materials}

Polypropylene random copolymer (PPR) procured from Borouge Pte. Ltd, UAE was used as a matrix (details are given in supporting information, see Fig. S1). PPR has a melt flow index of $0.3 \mathrm{~g} / 10 \mathrm{~min}$ 
(at $230{ }^{\circ} \mathrm{C} / 2.16 \mathrm{~kg}$ ), melting temperature of $147^{\circ} \mathrm{C}$ and crystallinity of $30 \%$. The MWCNTs used in this study were supplied by Applied Nanostructured Solution, LLC. They were grown by chemical vapor deposition (CVD) route [35] on glass fiber substrates [36]. The average length and outer diameter of MWCNTs were observed to be $\sim 30 \mu \mathrm{m}$ and $\sim 12$ $\mathrm{nm}$, respectively. Thermogravimetric analysis (TGA) was used to quantify the purity of MWCNT, and it was observed to be $86 \%$. PPR is used in this study in place of homo-polymer PP as it offers processing and economic benefits (PPR is cheaper and has low processing temperature and better mechanical properties compared to PP). The basic mechanical properties of PPR and MWCNT are given in Table S1.

\section{Preparation of PPR/MWCNT nanocomposite filament feedstocks for 3D printing}

PPR/MWCNT nanocomposite filament feedstocks were prepared by melt-blending technique using corotating twin-screw extruder (Coperion ZSK 18, Germany). The specially designed screw, equipped with novel fractional mixing elements [FME] suitable for the processing polyolefin was used in extruder which facilities better mixing of MWCNTs with PPR. This was equipped with a screw of $18 \mathrm{~mm}$ diameter and $\mathrm{L} / \mathrm{D}$ ratio of 40 . The temperature in the first, third, fifth, seventh and ninth zone was kept at $170,190,210,230$, and $230{ }^{\circ} \mathrm{C}$, respectively, while the die temperature was kept at $250{ }^{\circ} \mathrm{C}$ and screw speed was $200 \mathrm{rpm}$ [37]. Before compounding, PPR and MWCNTs were vacuum dried at $100{ }^{\circ} \mathrm{C}$ for $6 \mathrm{~h}$. For better mixing of MWCNTs in PPR matrix, both the materials were manually mixed in the presence of solvent (acetone). Due to the presence of solvent, MWCNTs get coated on the surface of PPR pellets. The polymer nanocomposites extruded using circular die of $1.80 \mathrm{~mm}$ to make 3D printable filaments. To ensure a consistent filament diameter of $1.74 \mathrm{~mm}$, speed roller was used (Fig. 1a). PPR/MWCNT nanocomposites were prepared by mixing varying amounts of MWCNT $(0,2,4,6,8 \mathrm{wt} \%)$ to PPR and are designated, respectively, as PPR-0, PPR-2, PPR-4, PPR-6 and PPR-8.

\section{Sample preparation using fused filament} fabrication (FFF) technique

3D printing of PPR/MWCNT nanocomposites was carried out using Creator Pro Flash Forge 3D printer, utilizing in-house developed filaments. CAD (using SolidWorks) software was used for creating 3D geometric models and Simplify3D-a slicer, was used to convert 3D models into G-codes. The laboratorymade PPR/MWCNT filament was fed into the printer nozzle with the help motor-driven pressure mechanism. With a customized metallic bed and a pressure sensitive tape, issues associated with poor adhesion of PPR to print bed were overcome to minimize shrinkage and warpage of printed samples. The optimized process parameters such as nozzle tip temperature $\left(230^{\circ} \mathrm{C}\right)$, layer height $(0.2 \mathrm{~mm})$, bed temperature $\left(115^{\circ} \mathrm{C}\right)$, infill density $(100 \%)$ and extrusion width $(0.4 \mathrm{~mm})$ were kept the same for all the samples. For morphological, mechanical, electrical and EMI shielding analyses, the test specimens were printed in two different printing directions i.e., $0^{\circ}$ and $90^{\circ}$ (Fig. S1). They have been designated as $0 /$ PPR-x or $90 / P P R-x$ where " 0 " and " 90 " refer to printing direction and " $\mathrm{x}$ " indicates the content of MWCNT in wt\%. For example, nanocomposites prepared with 4 and $8 \mathrm{wt} \%$ MWCNT loading in $0^{\circ}$ and $90^{\circ}$ printing directions are designated as $0 / \mathrm{PPR}-$ 4, 90/PPR-4 and 0/PPR-8, 90/PPR-8, respectively. Architected samples with frustum shaped surface features are referred to as frustum while the corresponding bulk samples, printed in $0^{\circ}$ and $90^{\circ}$ directions, are referred to as plain. The schematic representation of filament fabrication and3D printing along with tested samples (bulk and frustum shape) are shown in Fig. 1.

\section{Characterization}

The surface morphology of MWCNTs and the cryogenically fractured surface of PPR/MWCNT nanocomposites were analyzed using Nova Nano SEM 50 series, operated at $10 \mathrm{kV}$ to examine the microstructure and dispersion of MWCNT in the polymer matrix. These specimens were pre-coated with a thin layer of gold before SEM examination. Samples printed in two different directions $\left(0^{\circ}\right.$ and $90^{\circ}$ ) with specific dimension were used for Raman spectroscopy, AC electrical conductivity, EMI shielding measurement and flexural testing. Witech 
(a)
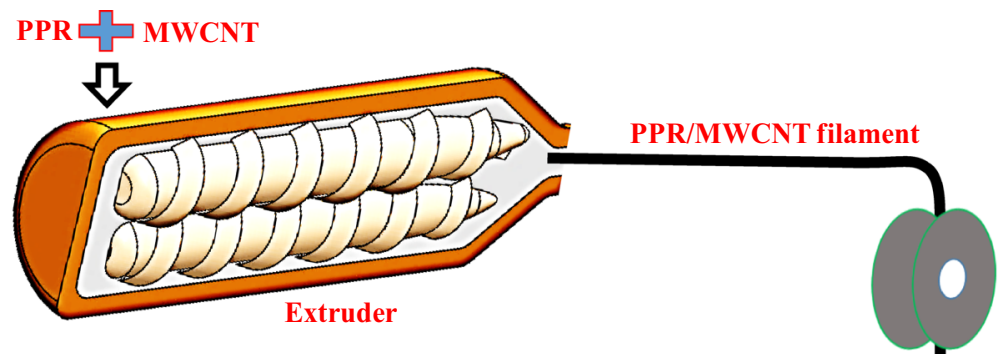

(c)
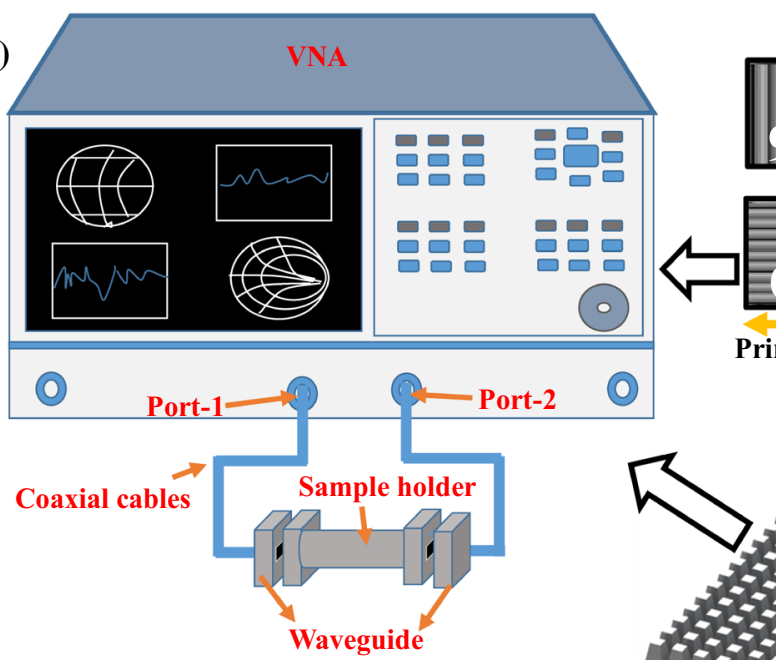

(d)

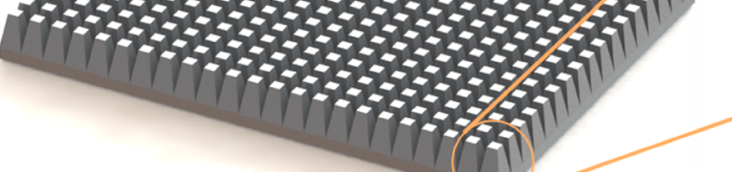

(b)

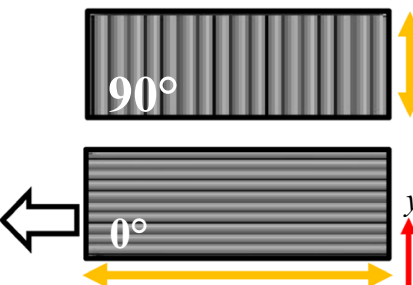

Printing

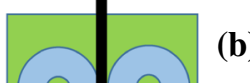

Printing direction $x$
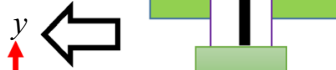

3D printer
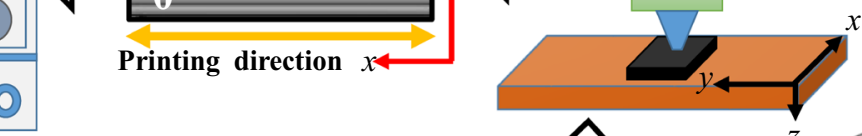

3D printed (frustum shaped) surface architected structure

Figure 1 Schematic representation of a filament fabrication process $\mathbf{b}$ 3D printing of PPR/MWCNT nanocomposites $\mathbf{c}$ VNA to measure EMI shielding effectiveness and $\mathbf{d}$ surface architected 3D printed samples.

Alpha 300RAS Raman spectrometer (wavelength $532 \mathrm{~nm}$ ) was used to investigate the structure of PPR/MWCNT nanocomposites. The spectra were recorded with Raman shift between 100 and $3500 \mathrm{~cm}^{-1}$ for PPR/MWCNT nanocomposites and 700 to $3500 \mathrm{~cm}^{-1}$ for neat PPR. The AC electrical conductivity of PPR/MWCNT nanocomposites was measured via a precision GW Instek LCR meter with Agilent E16451B probes over $20 \mathrm{~Hz}-10^{7} \mathrm{~Hz}$ frequency. For the measurement purpose, the rectangular samples of size $22.9 \mathrm{~mm} \times 10.2 \mathrm{~mm} \times 2 \mathrm{~mm}$ were used.

The EMI shielding response of PPR/MWCNT nanocomposites was performed using Vector Network Analyzer (Agilent E8362B) in the microwave frequency range of $8.2-12 \mathrm{GHz}$ (X-band). For this purpose, the rectangular samples with the dimension $22.9 \mathrm{~mm} \times 10.2 \mathrm{~mm} \times 2 \mathrm{~mm}$ were fabricated in two print directions i.e., $0^{\circ}$ and $90^{\circ}$. Furthermore, to understand shielding behavior of surface architected samples, two types of test samples were prepared, one was parallelepiped with flat surfaces $(22.9 \mathrm{~mm} \times 10.2 \mathrm{~mm} \times 3.8 \mathrm{~mm})$, and the other sample has frustum shaped surface features on one side of the sample. Each frustum has a square base $(2.0 \mathrm{~mm} \times 2.0 \mathrm{~mm})$, square top $(1.0 \mathrm{~mm} \times 1.0 \mathrm{~mm})$ and a height of $2.8 \mathrm{~mm}$. The characteristic geometry along with the dimension of 3D printed test samples with frustum shaped surface features is schematically shown in Fig. 1d. Test samples were inserted into a copper sample holder connected between the waveguide flanges of VNA. Before the measurement, twoport calibration was performed using the standard procedure to neglect any power redistribution and loss due to sample. From the measurements of Sparameters, the reflection, absorption, and transmission losses as well as the shielding effectiveness (SE) of the material were evaluated. Micro-computed 
tomography ( $\mu \mathrm{CT}$ ) (nanotom m ${ }^{\circledR}$ system) was used to quantify the interfacial defects and internal morphology along the thickness of the samples (in the zdirection). Flexural properties of nanocomposites were evaluated via a three-point flexural test conducted on the specimen of size $80 \mathrm{~mm} \times 12.7$ $\mathrm{mm} \times 3.3 \mathrm{~mm}$ at a constant crosshead speed of $2 \mathrm{~mm} / \mathrm{min}$ over a span of $50 \mathrm{~mm}$ between the supports by using Zwick-Roell universal testing machine at room temperature as per ASTM D790. The flexural stress $\sigma_{f}$ and the flexural strain $\varepsilon_{f}$ on the outer layer at mid-span as well as the modulus of elasticity $E_{B}$ in bending were determined as

$\sigma_{f}=3 \mathrm{PL} / 2 \mathrm{bd}^{2}$

$\varepsilon_{f}=6 \mathrm{Dd} / L^{2}$

$E_{B}=L^{3} m / 4 \mathrm{bd}^{3}$

where ' $L$ ' is the support span, ' $P$ ' is load ' $b$ ' is the width and ' $d$ ' is the depth of the test specimen. ' $D$ ' represents maximum deflection at the center and $m$ is the slope of the tangent of the linear region of loaddeflection curve.

\section{Results and discussion}

\section{Morphological characterization}

\section{Scanning electron microscopy (SEM)}

Figure 2a-e shows the SEM scans of cryogenically fractured surface of PPR/MWCNT nanocomposites comprising $0,2,4,6$ and 8 wt $\%$ of MWCNTs, respectively. SEM micrograph of neat PPR (Fig. 2a) shows the absence of MWCNTs, whereas the micrographs of composites (Fig. 2b, c) display the presence of MWCNTs (indicated by arrows) all over the polymer matrix and their abundance increase with loading level. It was observed that the MWCNTs are uniformly dispersed in the polymer matrix even at high loading (Fig. S2a, b), implying that the molten phase mixing within the extruder induced by shear is an efficient technique to produce truly nanoengineered composites. High magnification SEM micrographs (see supporting information; Fig. S2) confirm a very few entangled (rope-like) regions, the morphology of MWCNT networks and opening of MWCNT bundles [36]. Initially, MWCNTs are in the bundle form (Fig. S3). At higher MWCNT loading, only a few unconnected MWCNT links are observed indicating uncoiling and uniform dispersion of MWCNTs within the polymer matrix (Fig. S2) [38].

\section{Raman spectroscopic analysis of PPR/MWCNT} nanocomposites

Morphological changes with MWCNT content and printing directions of nanocomposite samples were analyzed through Raman spectroscopy (see Fig. 3). Figure 3a shows that PPR shows a sharp peak at $2880 \mathrm{~cm}^{-1}$ but this peak almost disappears in nanocomposite samples (see Fig. 3b, c). The absence of PPR signal in polymer nanocomposites exhibits the dephasing of the local motion of polymer chains and restricts the chain vibrational motion because of the interactions with MWCNT. Furthermore, Raman spectra of MWCNT and polymer nanocomposites display predominantly two peaks characterized as ' $D$ ' and ' $G$ ' bands. Interestingly, it can be noted that peak intensity and location of ' $D$ ' and ' $G$ ' bands are only depended on MWCNT loading and are almost independent of printing direction. Observant investigation of Raman spectra of MWCNT and polymer nanocomposites, printed in $0^{\circ}$ and $90^{\circ}$ directions, reveal that as the loading of MWCNT increases, the position of D-band shifts toward lower wave numbers with typical values from $1352 \mathrm{~cm}^{-1}$ (having 2 wt\% MWCNT) to $1345 \mathrm{~cm}^{-1}$ (having $8 \mathrm{wt} \%$ MWCNT) (Fig. 3b, c); almost the same in both nanocomposites $\left(0^{\circ}\right.$ and $\left.90^{\circ}\right)$. This behavior confirms the local stresses and interactions between the MWCNT and PPR matrix [39, 40]. Furthermore, the intensity ratio of D-band over G-band $\left(I_{D} / I_{G}\right)$ of MWCNT and polymer nanocomposites are also quantified and found that $I_{D} / I_{G}$ ratio for MWCNT is 1.18 confirming that MWCNT has more disordered structure as the MWCNTs are present in the form of bundles or ropes (see SEM micrograph in Fig. S3 in supplementary information). Interestingly, for polymer nanocomposites, $I_{D} / I_{G}$ ratio is always less than one and increases (from 0.79 to 88) with MWCNT loading, revealing the more ordered structure compared to MWCNT. This is due to MWCNT bundle opening (confirmed from SEM micrographs; Fig. S2) during processing as a result of shear effect. It is also important to note that $\mathrm{I}_{\mathrm{D}} / \mathrm{I}_{\mathrm{G}}$ ratio of nanocomposites increases with MWCNT loading. This variation reflects processing induced disorder on MWCNTs' outer walls. The opening of MWCNT rope structure 
Figure 2 SEM micrographs of PPR/MWCNT

nanocomposites (where $\mathrm{a}, \mathrm{b}, \mathrm{c}$, $\mathrm{d}$ and e correspond to $0,2,4,6$ and $8 \mathrm{wt} \%$ of MWCNT loading, respectively). Arrows indicate the presence of MWCNT.

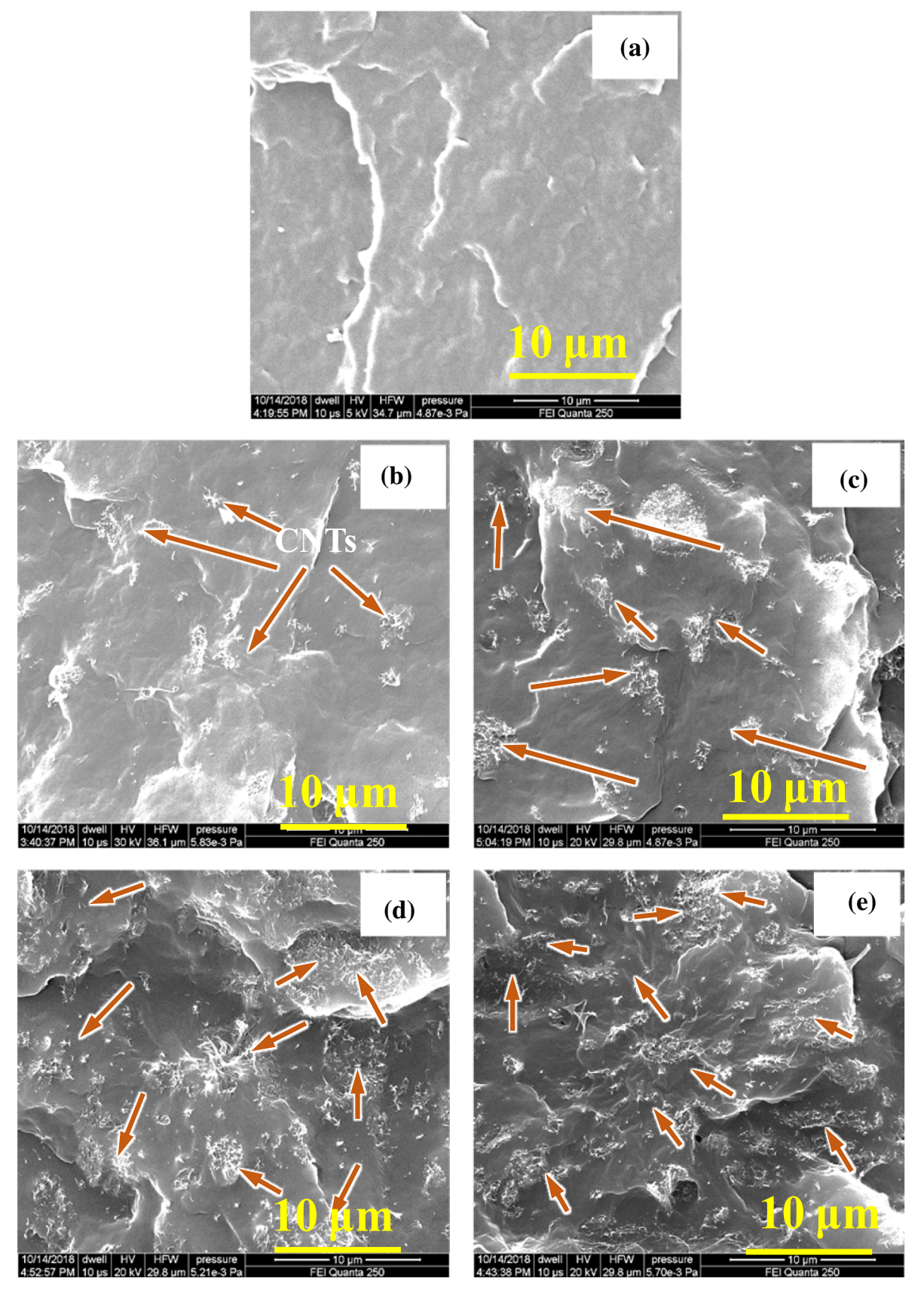

and generation of defects over MWCNTs' walls (due to high shearing encountered during melt mixing) suggest improved dispersion of MWCNT in PPR matrix [4, 41]. Therefore, they may contribute to efficient stress transfer and EMI shielding behavior [4].

\section{AC conductivity}

The AC conductivity measurements of PPR/ MWCNT nanocomposites as a function of frequency (from 20 to $10^{7} \mathrm{~Hz}$ ) and MWCNT loading are shown in Fig. 4. These plots clearly reveal significant improvement in conductivity of PPR with MWCNT loading (2-8 wt\%). A sharp increase in conductivity (from $10^{-13}$ to $10^{-7} \mathrm{~S} / \mathrm{cm}$ ) of nanocomposites is observed over the frequency range considered at 2 wt $\%$ MWCNT loading for samples printed in both directions (i.e., $0^{\circ}$ and $90^{\circ}$ ). The sudden rise in the conductivity of nanocomposites confirms the formation of conductive network and attainment of percolation threshold. Interestingly, Fig. 4 shows that the 


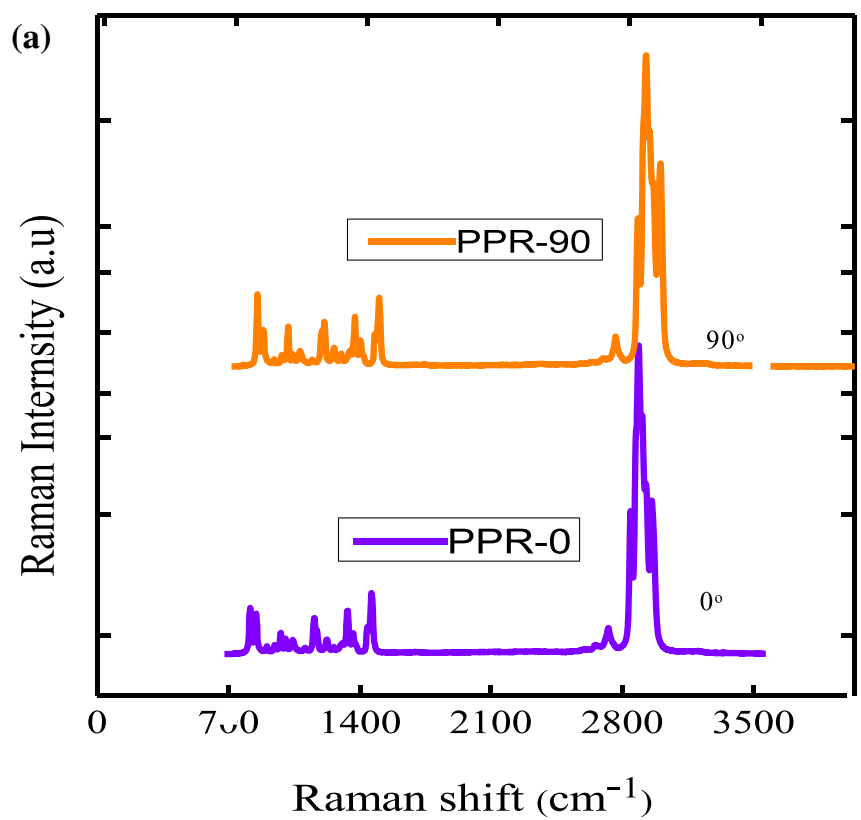

(b)

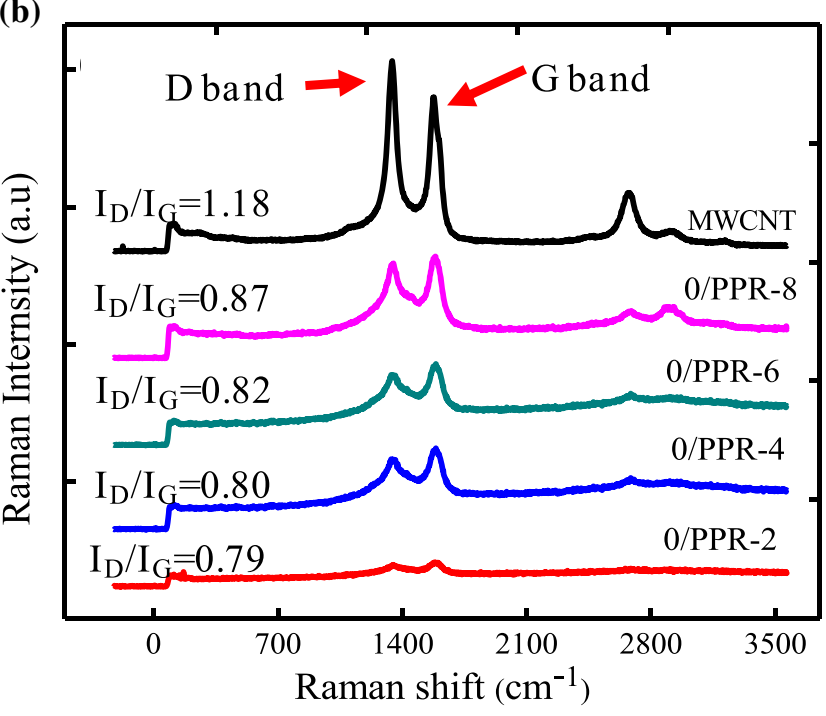

(c)

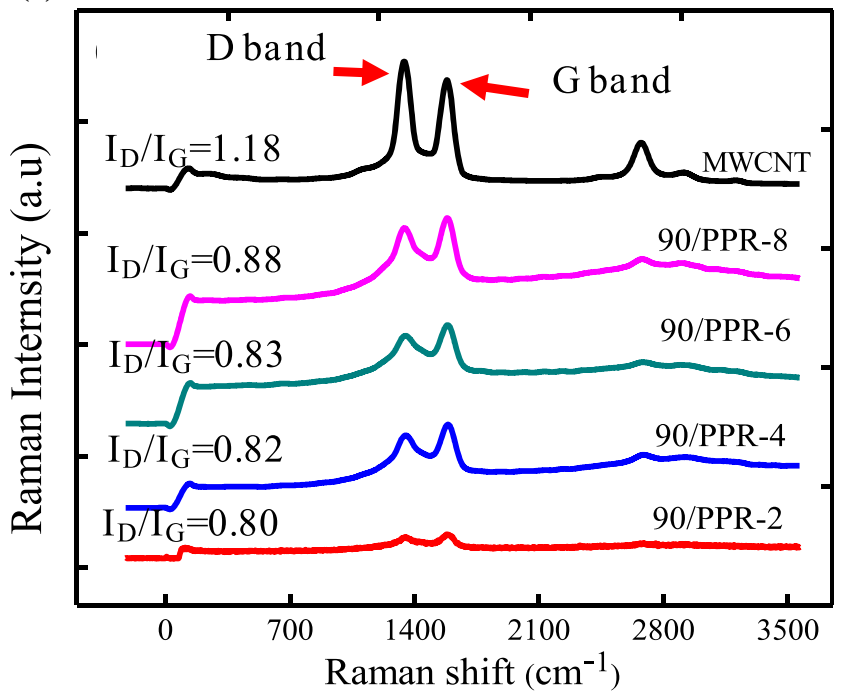

Figure 3 a Raman spectra of PPR printed in $0^{\circ}$ and $90^{\circ}, \mathbf{b}$ and $\mathbf{c}$ Raman spectra of PPR/MWCNT nanocomposites printed in $0^{\circ}$ and $90^{\circ}$ directions, respectively.

conductivity changes with frequency. The conductivity of neat PPR continuously increases with frequency $\left(20-10^{7} \mathrm{~Hz}\right)$ and approaches almost that of nanocomposites having $2 \mathrm{wt} \%$ MWCNT loading at higher frequency. The PPR nanocomposites having 2 and $4 \mathrm{wt} \%$ MWCNT loadings show frequency independency up to $10^{4} \mathrm{~Hz}$ but thereafter, conductivity values increase and attain almost similar values at higher frequency. In contrast, PPR nanocomposites 0/PPR-6 or 90/PPR-6 and 0/PPR-8 or 90/PPR-8 show a sharp increase in conductivity up to $10^{3} \mathrm{~Hz}$ and thereafter marginal increment is observed with increase in frequency [42].The change in conductivity with frequency in disordered material is usually described through polarization effect between clusters and anomalous diffusion within each cluster. Once the electrical percolation is established, the conductivity of the system at lower frequency regime is determined via conducting paths of the percolating clusters and is independent of the frequency, whereas at high frequency, the capacitive effect between clusters on the conductivity becomes 

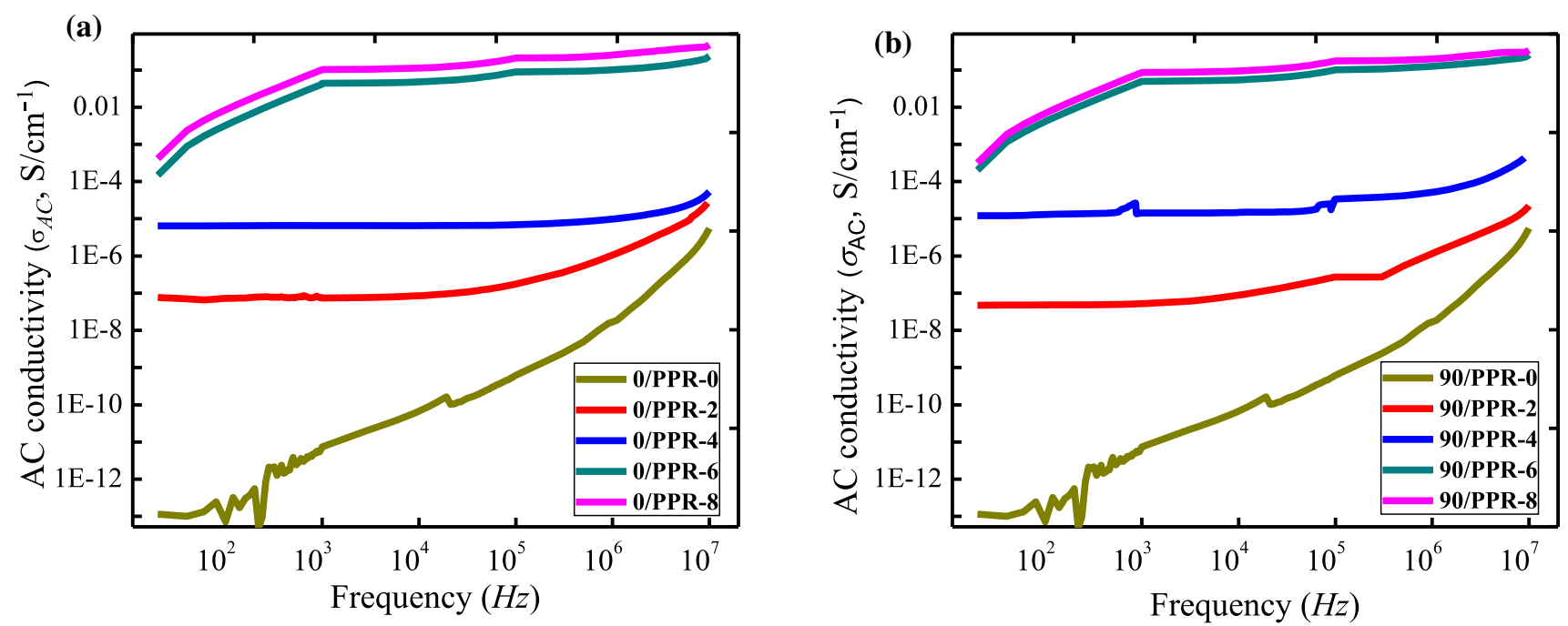

(c)

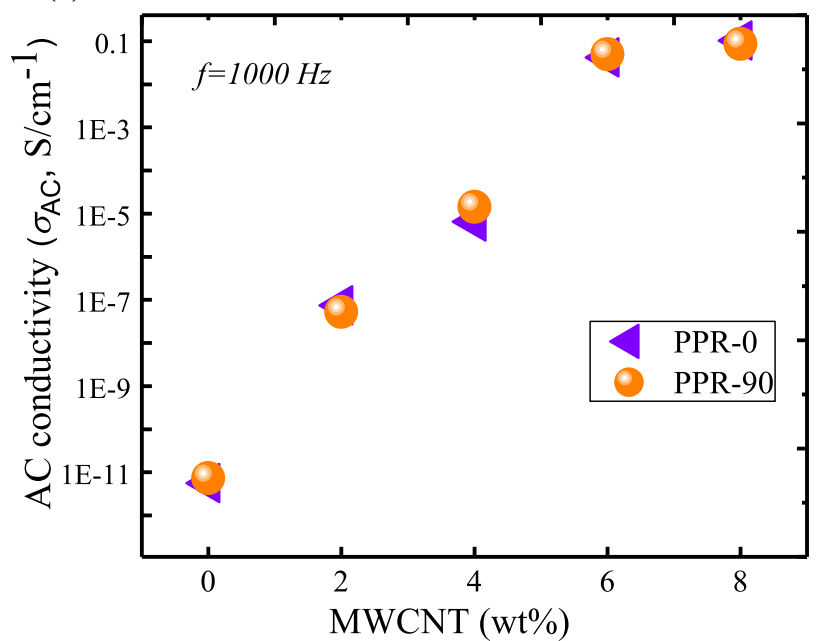

Figure $4 \mathbf{a}$ and $\mathbf{b}$ measured AC electrical conductivity $\left(\sigma_{\mathrm{AC}}\right)$ as a function of frequency for PPR/MWCNT nanocomposites printed in $0^{\circ}$ and $90^{\circ}$ directions, respectively c AC conductivity with respect to MWCNT loading at a particular frequency (1000 $\left.\mathrm{Hz}\right)$.

significant, as a result, conductivity increases. Similar behavior was also reported by Tjong et al. for PP/ MWNCT composites and other researchers [43-45]. Furthermore, the PPR nanocomposites do not show printing direction-dependence (i.e. $0^{\circ}$ and $90^{\circ}$ ) on AC conductivity (Fig. 4c) which is in line with Raman spectroscopy results as discussed in the previous section (Fig. 3).

\section{EMI shielding response}

The ability of a shielding material to suppress EM waves can be expressed as the ratio of impinging energy (of electromagnetic waves) to the residual energy. The EMI attenuation offered by a shielding material may be due to reflection and absorption of the incident wave via various dissipation mechanisms and multiple reflections of the wave. Therefore, shielding effectiveness (SE) of material or attenuation of an electromagnetic wave occurs by three losses, namely, absorption loss $\left(\mathrm{SE}_{A}\right)$, reflection loss $\left(\mathrm{SE}_{R}\right)$ and multiple reflection loss $\left(\mathrm{SE}_{M}\right)$. SE expressed as [3, 46-48]

$$
\begin{aligned}
\mathrm{SE}(d B) & =\left(\mathrm{SE}_{R}+\mathrm{SE}_{A}+\mathrm{SE}_{M}\right)=10 \log _{10}\left(\frac{P_{T}}{P_{I}}\right) \\
& =20 \log _{10}\left(\frac{E_{T}}{E_{I}}\right)
\end{aligned}
$$

where $P_{T}\left(E_{T}\right)$ and $P_{I}\left(E_{I}\right)$ are the powers (electric field intensity) of the transmitted and the incident EM 
waves, respectively. As the power of transmitted wave is always less than that of incident wave, the SE is a negative quantity, and it increases with more negative values. It is important to note that the multiple reflection loss $\left(\mathrm{SE}_{\mathrm{M}}\right)$ can be ignored if absorption loss $\left(\mathrm{SE}_{\mathrm{A}}\right)$ of EMI shielding material is higher than $-10 \mathrm{~dB}$ and Eq. 4 then can be recast as

$\mathrm{SE}(d B)=\mathrm{SE}_{R}+\mathrm{SE}_{A}$

Furthermore, $S E_{R}$ and $S E_{A}$ can be expressed in the form of reflectance $\left(R=\left|S_{11}\right|^{2}\right)$ and transmittance $\left(T=\left|S_{21}\right|^{2}\right)$ as given below

$S E_{R}=10(\log (1-R)$

$S E_{A}=10(\log [(T /(1-R)]$

where $\mathrm{S}_{11}$ and $\mathrm{S}_{21}$ are S-parameters (scattering parameters) and can be measured with the vector network analyzer (VNA).

Figure $5 \mathrm{a}, \mathrm{b}$ displays the frequency-dependent total shielding effectiveness (SE) of nanocomposites printed in $0^{\circ}$ and $90^{\circ}$ directions, respectively, while Fig. $5 \mathrm{c}-\mathrm{e}$ shows the total shielding effectiveness $\left(\mathrm{SE}_{T}\right)$, shielding effectiveness due to reflection $\left(\mathrm{SE}_{R}\right)$ and shielding effectiveness due to absorption $\left(\mathrm{SE}_{A}\right)$ of nanocomposites as a function of MWCNT loading for samples printed in $0^{\circ}$ and $90^{\circ}$ directions, respectively. From Fig. 5a, b, it is clear that PPR sample displays lower SE values and behaves as transparent material toward incident microwave rays, with no evidence of printing direction-dependence, and negligible attenuation (with maximum $\mathrm{SE}$ is $-2 \mathrm{~dB}$ ). However, loading of MWCNTs contributes to shielding effectiveness of both 0/PPR and 90/PPR nanocomposites, and they display the SE of $-19 \mathrm{~dB}(\sim 99 \%$ attenuation) and $-38 \mathrm{~dB}(\sim 99.9 \%$ attenuation) for $8 \mathrm{wt} \%$ MWCNT loading, respectively. This can be attributed to the formation of the conducting networks within the PPR matrix. Moreover, the measured shielding performance indicates that 90/PPR nanocomposites have superior SE compared to 0/PPR nanocomposites. These results signify the tunable shielding performance of AM-enabled nanocomposites. Interestingly, these results also suggest that other factors (apart from conduction and dielectric loss) may also govern achieved SE. To explore further, $\mathrm{SE}_{T}$ is divided into reflection $\left(\mathrm{SE}_{R}\right)$ and absorption components $\left(\mathrm{SE}_{A}\right)$ through scattering parameters $\left(\mathrm{S}_{11}\right.$ and $\mathrm{S}_{21}$ ). Figure $5 \mathrm{~d}$, e shows that both $\mathrm{SE}_{R}$ and $\mathrm{SE}_{A}$ increase with MWCNT content. The increase rate of
$\mathrm{SE}_{A}$ is much higher than that of $\mathrm{SE}_{R}$ in both nanocomposites $\left(0^{\circ}\right.$ and $90^{\circ}$ samples $)$ with relative dominance of $\mathrm{SE}_{A}$ over $\mathrm{SE}_{R}$ with an increase in MWCNT wt\%. We can also quantify from Fig. 5d, e that $\mathrm{SE}_{R}$ is almost the same in both cases (see Tables 1 and 2) confirming that conduction effect is similar, MWCNT distribution and network formation are almost the same and unaffected by printing direction. However, $\mathrm{SE}_{A}$ (Fig. 5d, e) shows variation with MWCNT content and printing direction. $\mathrm{SE}_{A}$ increases with MWCNT loading indicating that the interfacial polarization effects and input impedance matching of nanocomposites allow more incident radiation inside the shielding material that can be suppressed through absorption mechanism. The absorption loss is higher for nanocomposites printed in $90^{\circ}$ direction. This is due to the presence of more interfaces or active sites which act as polarization centers due to space charge localization occurring via Maxwell-Wagner interfacial polarization, (see Fig. 6) [49]. Besides, as evident from SEM micrographs (see supporting information Fig. S4) and also shown schematically in Fig. 6, $90^{\circ}$ printed nanocomposites show highly distributed incident rays because of the les $\mathrm{SE}_{R}$ extent of interfacial voids between the adjacent beads compared to $0^{\circ}$ direction nanocomposites (Fig. 6a) that minimize the radiation leaking, providing more sites for multiple internal reflections (MIR) (the microwave transparent space denoted by white line and MIR denoted by randomly pointed yellow arrows in Fig. 6a, b).

Furthermore, to validate the observations from SEM micrographs, the internal morphology and interfacial defects (along the thickness of test samples) of $0^{\circ}$ and $90^{\circ}$ samples are analyzed using microcomputed tomography $(\mu \mathrm{CT})$ images recorded through nanoCT system (phoenix nanotom $\mathrm{m}{ }^{\circledR}$ ). $\mu \mathrm{CT}$ is an efficient technique to justify the EMI shielding observations since it delivers detailed 3D microstructure in the form of 2D images from volume [50]. As we can see from $\mu \mathrm{CT}$ images (Fig. S5) and videos (SV1 and SV2 for $0^{\circ}$ and $90^{\circ}$ directions, respectively) that the interfacial defects between the beads in $0^{\circ}$ samples are higher compared to $90^{\circ}$ samples along the printing direction. Although, some interfacial defects are observed through $\mu \mathrm{CT}$ in $90^{\circ}$ samples, the extent of voids or defects noticed is less, and are randomly distributed in a few zones of the test sample volume with a low defect fraction. The greater extent of defects in $0^{\circ}$ direction samples is 
(a)

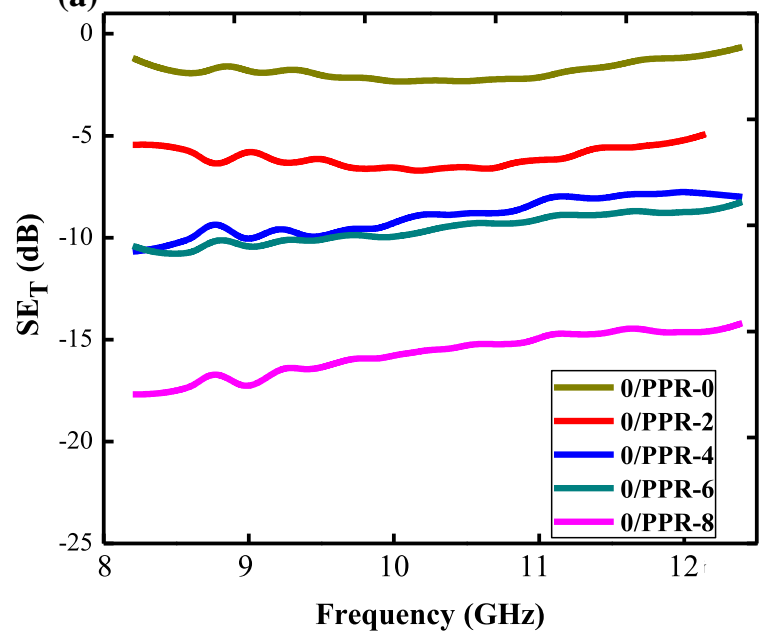

(b)

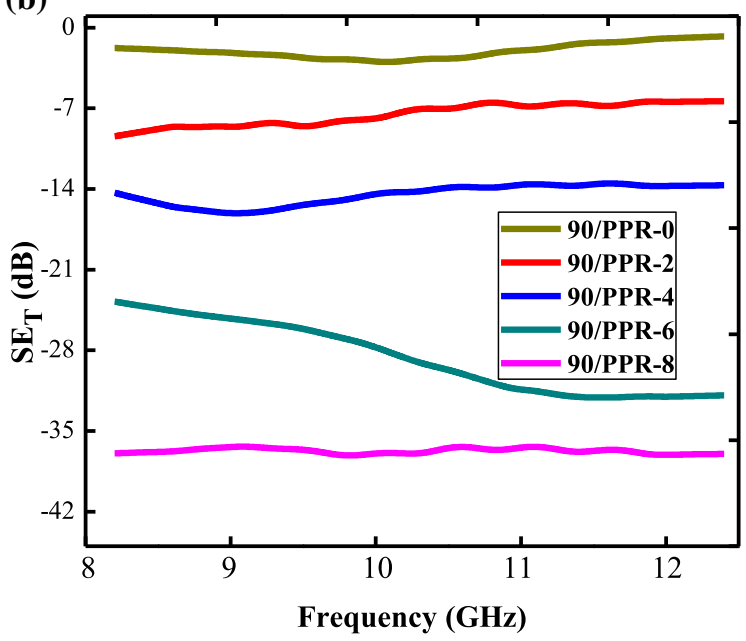

(c)

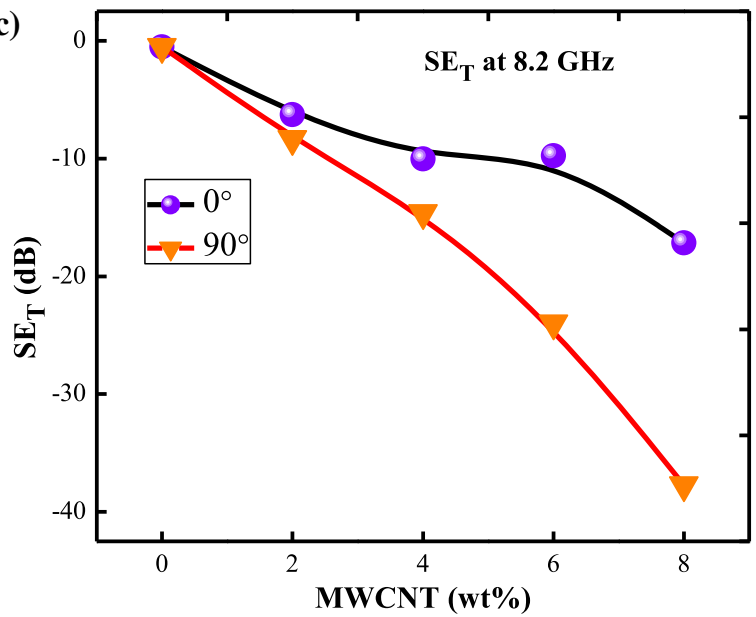

(d)

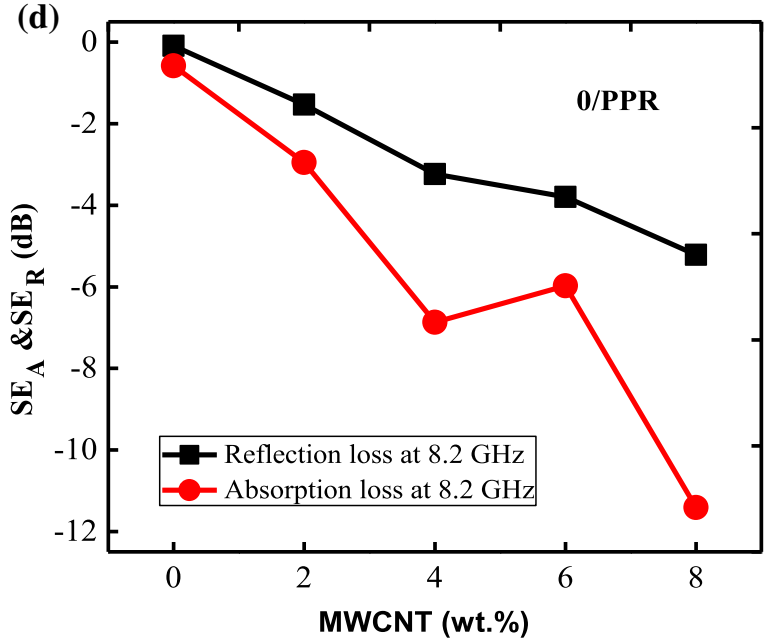

Figure $5 \mathbf{a}$ and $\mathbf{b}$ show EMI SE with respect to frequency for PPR/MWCNT nanocomposites printed in $0^{\circ}$ and $90^{\circ}$ directions, respectively, while $\mathbf{c}, \mathbf{d}$ and $\mathbf{e}$ show total shielding effectiveness, shielding effectiveness due to absorption (absorption loss) and

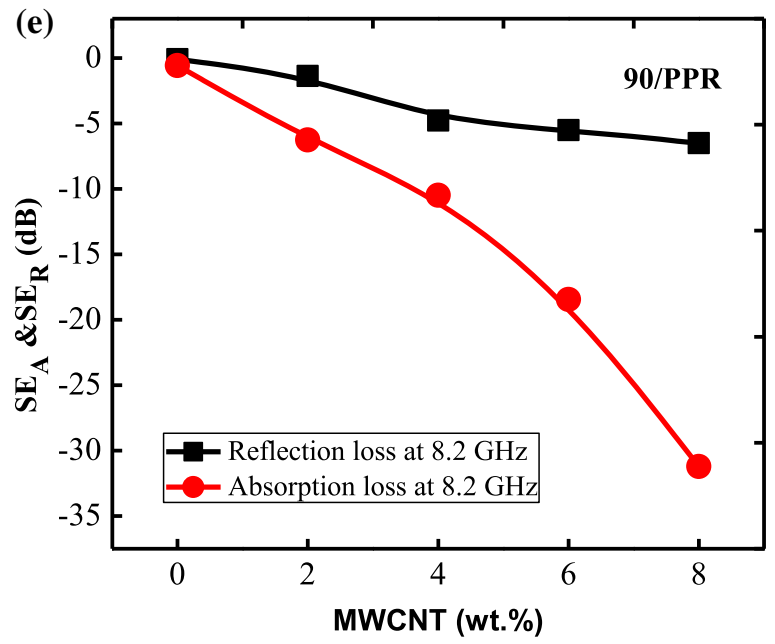

shielding effectiveness due to refection (reflection loss) of nanocomposites with respect to MWCNT loading at a particular frequency $(8.2 \mathrm{GHz})$. 
Table 1 Summary of electrical conductivity, reflection loss $\left(\mathrm{SE}_{R}\right)$, absorption loss $\left(\mathrm{SE}_{A}\right)$, total shielding effectiveness $\left(\mathrm{SE}_{T}\right)$ and flexural properties of PPR and PPR/MWCNT nanocomposites printed in $0^{\circ}$ direction

\begin{tabular}{llllllll}
\hline $\begin{array}{l}\text { Sample } \\
\text { designation }\end{array}$ & $\begin{array}{l}\text { Electrical } \\
\text { conductivity }(\mathrm{S} / \\
\mathrm{cm}) \text { at } 1000 \mathrm{~Hz}\end{array}$ & $\begin{array}{l}\mathrm{SE}_{R} \\
(\mathrm{~dB}) \text { at } \\
8.2 \mathrm{GHz}\end{array}$ & $\begin{array}{l}\mathrm{SE}_{A} \\
(\mathrm{~dB}) \text { at } \\
8.2 \mathrm{GHz}\end{array}$ & $\begin{array}{l}\mathrm{SE}_{T} \\
(\mathrm{~dB}) \text { at } \\
8.2 \mathrm{GHz}\end{array}$ & $\begin{array}{l}\text { Elastic modulus } \\
(\mathrm{MPa})\end{array}$ & $\begin{array}{l}\sigma_{\mathrm{fM}}(\max . \text { stress }) \\
(\mathrm{MPa})\end{array}$ & $\begin{array}{l}\varepsilon_{\mathrm{fM}}(\mathrm{strain} \text { at max. } \\
\text { force) }(\%)\end{array}$ \\
\hline 0/PPR-0 & $7.4 \mathrm{E}-12$ & -0.09 & -0.58 & -0.67 & $739 \pm 10$ & $25.17 \pm 2$ & $8.37 \pm 0.8$ \\
0/PPR-2 & $7.4 \mathrm{E}-8$ & -1.53 & -2.95 & -4.48 & $707 \pm 27(-4.3 \%)$ & $27.27 \pm 1.8(+8 \%)$ & $8.25 \pm 1(-1.4 \%)$ \\
0/PPR-4 & $6.6 \mathrm{E}-6$ & -3.24 & -6.87 & -10.10 & $876 \pm 34(+18 \%)$ & $31.47 \pm 2.1(+24 \%)$ & $8.22 \pm 0.9(-1.0 \%)$ \\
0/PPR-6 & 0.04 & -3.80 & -5.98 & -9.77 & $1006 \pm 12(+36 \%)$ & $38.47 \pm 1.2(+52 \%)$ & $8.09 \pm 1.3(-3.0 \%)$ \\
0/PPR-8 & 0.10 & -5.21 & -11.41 & -16.63 & $1243 \pm 23(+68 \%)$ & $41.27 \pm 0.7(+64 \%)$ & $8.01 \pm 1.1(-4.0 \%)$ \\
\hline
\end{tabular}

Table 2 Summary of electrical conductivity, reflection loss $\left(\mathrm{SE}_{R}\right)$, absorption loss $\left(\mathrm{SE}_{A}\right)$, total shielding effectiveness $\left(\mathrm{SE}_{T}\right)$ and flexural properties of $\mathrm{PPR}$ and $\mathrm{PPR} / \mathrm{MWCNT}$ nanocomposites printed in $90^{\circ}$ direction

\begin{tabular}{|c|c|c|c|c|c|c|c|}
\hline $\begin{array}{l}\text { Sample } \\
\text { designation }\end{array}$ & $\begin{array}{l}\text { Electrical } \\
\text { conductivity } \\
(\mathrm{S} / \mathrm{cm}) \text { at } \\
1000 \mathrm{~Hz}\end{array}$ & $\begin{array}{l}\mathrm{SE}_{R} \\
(\mathrm{~dB}) \text { at } \\
8.2 \mathrm{GHz}\end{array}$ & $\begin{array}{l}\mathrm{SE}_{A} \\
(\mathrm{~dB}) \text { at } \\
8.2 \mathrm{GHz}\end{array}$ & $\begin{array}{l}\mathrm{SE}_{T}(\mathrm{~dB}) \\
\text { at } \\
8.2 \mathrm{GHz}\end{array}$ & $\begin{array}{l}\text { Elastic modulus } \\
(\mathrm{MPa})\end{array}$ & $\sigma_{\mathrm{fM}}(\max$. stress $)(\mathrm{MPa})$ & $\begin{array}{l}\varepsilon_{\mathrm{fM}}(\text { strain at } \max . \\
\text { force })(\%)\end{array}$ \\
\hline 90/PPR-0 & $7.38 \mathrm{E}$ & -0.09 & -0.58 & -0.673 & $582 \pm 22$ & 16 & 8.3 \\
\hline 90/PPR-2 & $5.23 \mathrm{E}-8$ & -1.39 & -6.27 & -7.66 & $590 \pm 15(+1.3 \%)$ & $18.36 \pm 1.4(+8.0 \%)$ & $8.57 \pm 0.5(+2.7 \%)$ \\
\hline 90/PPR-4 & $1.43 \mathrm{E}-5$ & -4.79 & -10.49 & -15.28 & $602 \pm 16(+3.0 \%)$ & $25.95 \pm 0.6(+47.0 \%)$ & $9.36 \pm 0.3(+12.23 \%)$ \\
\hline 90/PPR-6 & 0.05 & -5.53 & -18.45 & -23.98 & $622 \pm 27(+6.8 \%)$ & $24.67 \pm 1.2(+41.0 \%)$ & $8.89 \pm 1.1(+6.59 \%)$ \\
\hline 90/PPR-8 & 0.09 & -6.51 & -31.23 & -37.73 & $727 \pm 7(+24.0 \%)$ & $29.26 \pm 1.8(+58.0 \%)$ & $8.30 \pm 1.7(-1.1 \%)$ \\
\hline
\end{tabular}

because of larger fabrication area in the $x-y$ plane (more time interval to lay succeeding layer) and hence proceeding layer (bead) had enough time to solidify [50]. The subsequent horizontal layer (along the $x$-axis) was deposited on the already solidified surface (bead). As the surface was already solidified, the incoming polymer melt (layer) could not properly stick to the surface encouraging defects formation at the interface [51, 52]. The deposition of molten polymer in $90^{\circ}$ direction occurred on the surface of the earlier horizontal layer that was not fully solidified and promoted an acceptable degree of interfacial adhesion between the subsequent horizontal layer (beads) in the fabrication direction. The non-uniform printing-induced internal voids or defects in the $0^{\circ}$ samples might be responsible for more transmission loss. In contrast, because of defect-free morphology in $90^{\circ}$ samples, more EM waves interact with MWCNT and once absorbed, due to multiple internal reflections (schematic diagram, Fig. 6), exhibits higher absorption loss. Therefore, superior attenuation in $90^{\circ}$ printed (90/PPR) nanocomposites may be due to the combined effect of improved polarization (and related losses), optimum conductivity (ohmic losses \& better impedance matching) and more dissipation via MIR phenomenon along with voids-free morphology. It is important to note that the addition of MWCNT also leads to reduced skin depth, suggesting that relatively thin EMI shield may be appropriate to provide the desired level of shielding effectiveness (Fig. S6).

\section{Electromagnetic shielding effectiveness of surface architected samples}

Figure 7 shows the EMI SE of 3D printed surface architected (frustum) and plain solid structures of PPR/MWCNT nanocomposites comprising 4 wt $\%$ MWCNTs. From Fig. $7 \mathrm{a}$, the plain sample $\left(\mathrm{SE}_{T}\right.$ values in the range of -28 to $-19 \mathrm{~dB}$ ) shows higher $\mathrm{SE}$ over frustum samples $\left(\mathrm{SE}_{T}\right.$ values in the range of -21 to $-14 \mathrm{~dB}$ ). The decrease in the SE of frustum sample may be due to the reduced number of conductive fillers (over all mass is less in frustum shaped sample). The relative density of frustum structure is observed to be $67 \%$. Similar behavior has been 


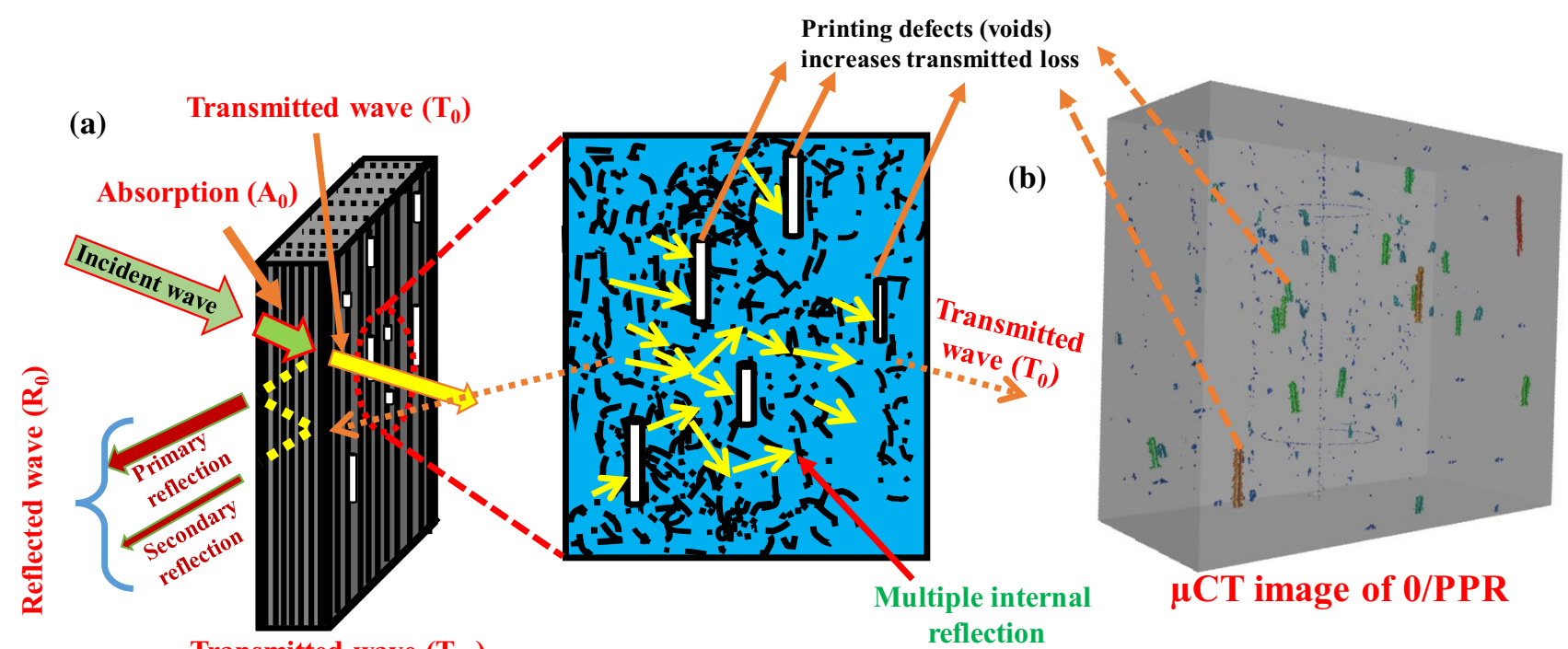

(c)

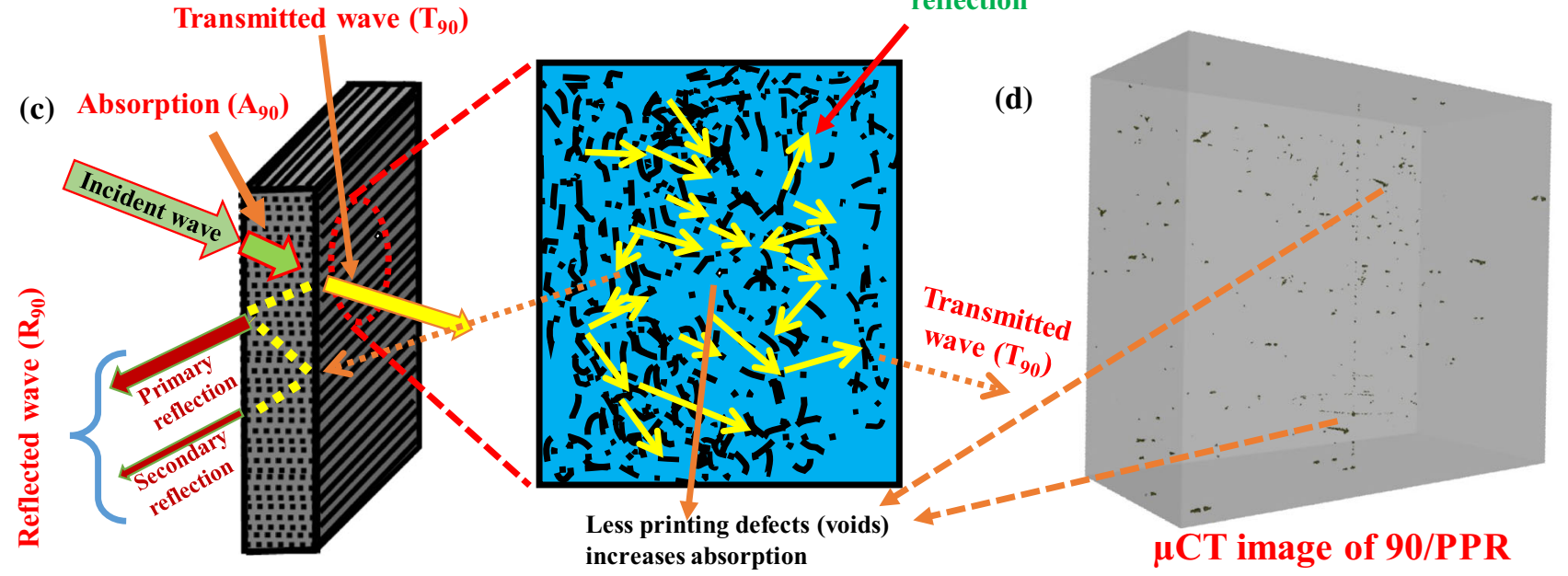
reflection

$$
\mathbf{A}_{0}<\mathbf{A}_{90}, \mathbf{R}_{0}=\mathbf{R}_{90} \text { and } \mathbf{T}_{0}>\mathrm{T}_{90}
$$

Figure 6 Schematic representation of the EMI shielding mechanism supported with $\mu \mathrm{CT}$ images for PPR/MWCNT nanocomposites printed in (a and $\mathbf{b}) 0^{\circ}$ and (c and $\left.\mathbf{d}\right) 90^{\circ}$ directions, respectively.

observed by Chizari et al. [27] wherein higher SE values for bulk samples compared to $3 \mathrm{D}$ printed scaffold structures were reported. Interestingly, it is also observed that the EMI SE of the surface architected sample increases with increasing frequency in X-band while EMI SE of plain solid structure increases up to $10 \mathrm{GHz}$ and decreases thereafter approaching that of the surface architected structures (Fig. 7a). The decrease in SE for bulk samples (plain) with frequency, may be due to capacitive effect within the disordered solid. For better understanding, the total shielding effectiveness is resolved into $\mathrm{SE}_{A}$ and $\mathrm{SE}_{R}$ components (Fig. $7 \mathrm{~b}, \mathrm{c}$ ) which reveal that both samples (plain and frustum) exhibit similar behavior of $\mathrm{SE}_{R}$ and show increasing trend with frequency, conforming the capacitive effect within the nanocomposites. It is interesting to note that $\mathrm{SE}_{R}$ (Fig. 7b) of frustum sample is higher than that of the plain sample at higher frequency, perhaps due to multiple surface reflections (MSR). $\mathrm{SE}_{A}$ and $\mathrm{SE}_{T}$ in Fig. 7c follow a similar trend, displaying higher SE of solid (plain) samples in the measured frequency range. The absorption shielding mechanism such as total internal reflections and interfacial polarization effects may be responsible for this behavior. In addition, decrease in dielectric constant at higher frequency may be responsible for decrease in $\mathrm{SE}_{A}$ (Fig. 7c). Similar SE behavior was also observed for the bulk samples (Fig. 5a, b) where SE slightly decreases or remains constant with increase in 
(a)

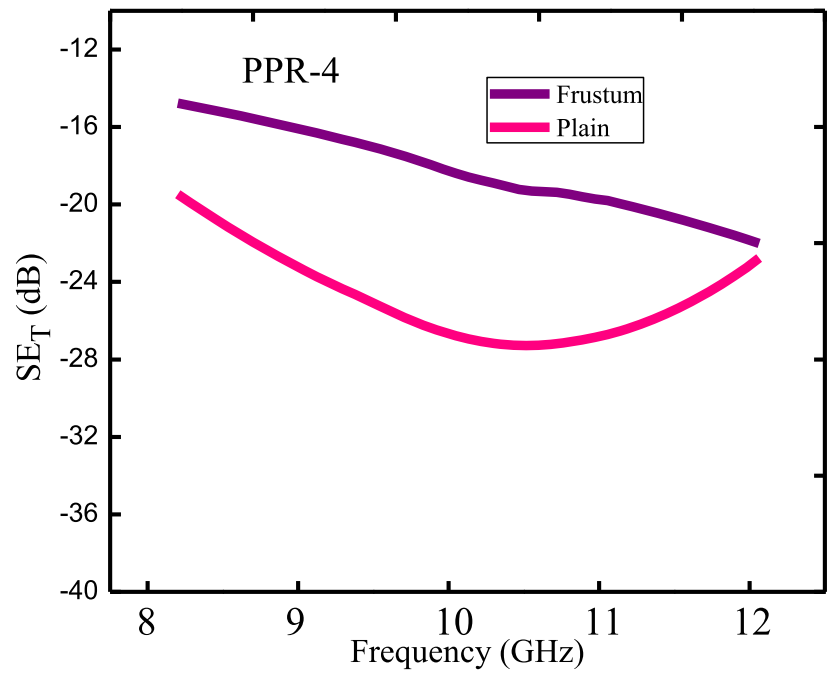

(b)

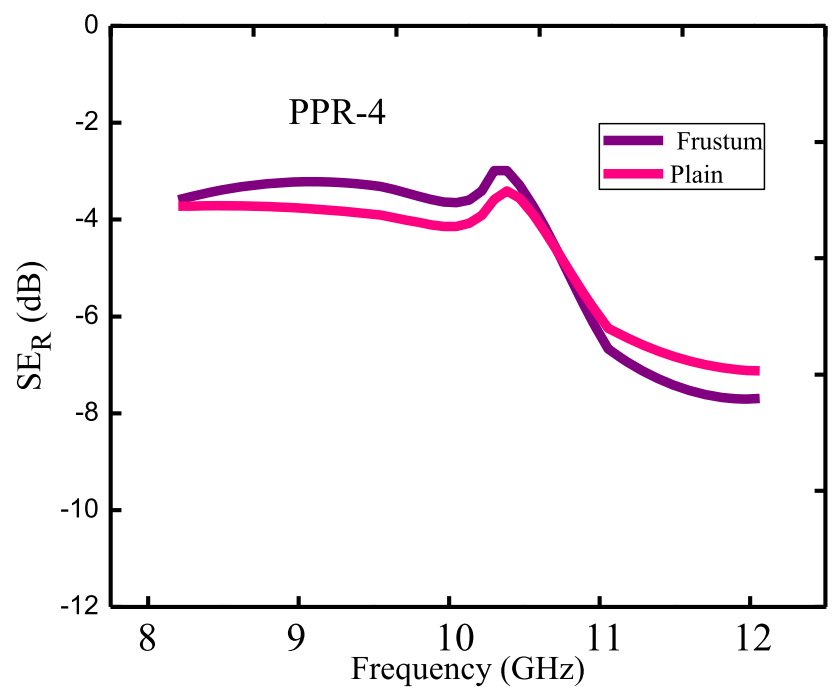

(c)

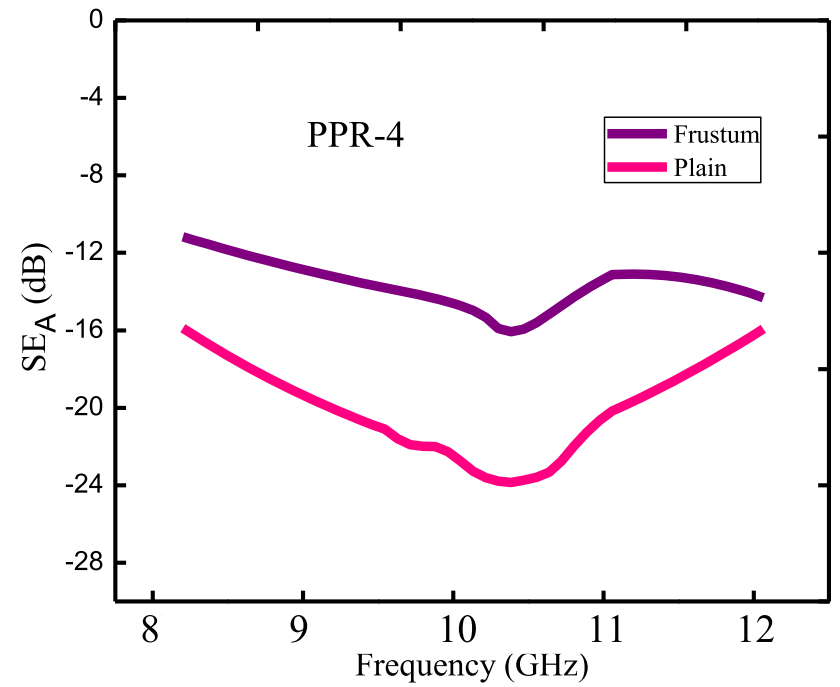

(d)

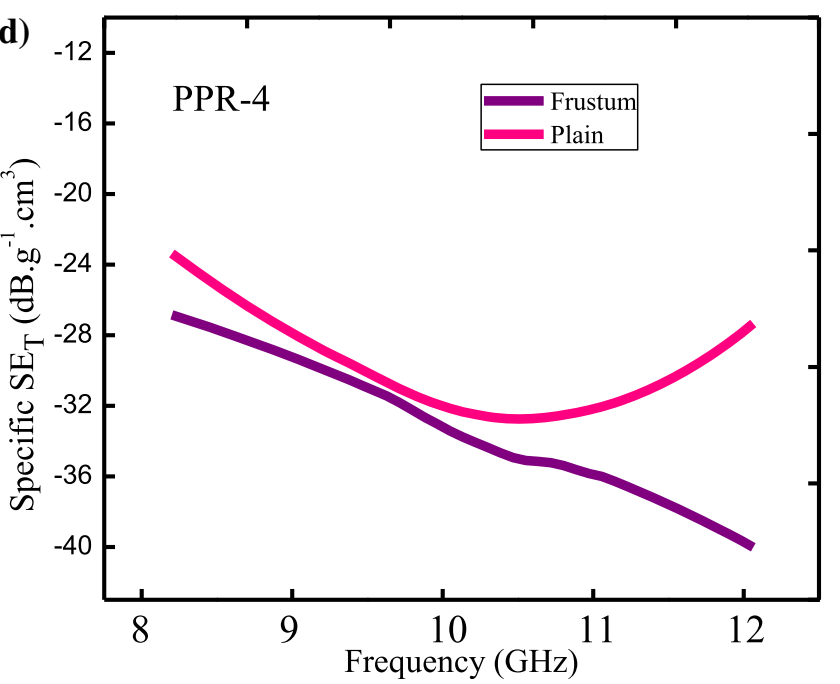


4 Figure 7 a Shielding effectiveness due to reflection $\left(\mathrm{SE}_{R}\right)$, b shielding effectiveness due to absorption $\left(\mathrm{SE}_{A}\right) \mathbf{c}$ total shielding effectiveness $\left(\mathrm{SE}_{T}\right)$ and $\mathbf{d}$ the specific total shielding effectiveness $\left(\mathrm{S} \mathrm{SE}_{T}\right)$ of the plain and surface architected structures fabricated via FFF process. Plain structure was printed in $0^{\circ}$ and $90^{\circ}$ directions layer by layer with the total thickness of $3.8 \mathrm{~mm}$ and surface architected was of same overall thickness with frustum shaped surface features.

frequency. Additionally, thickness of the sample may also play a role for the dominance of capacitive effect in plain sample.

Further, since total weight used for EMI shields is an important factor for various applications such as aircraft, satellite and portable electronic gadgets, the EMI shielding response of frustum structures is normalized by the density which we refer to as specific EMI SE (Fig. 7d). The total volume of the structure including the empty space is used to calculate the density of samples $[4,53]$. The specific EMI SE of the frustum structure increases at a higher rate with frequency compared to the plain solid samples with a maximum specific EMI SE $\sim-40 \mathrm{~dB} \mathrm{~g}^{-1} \mathrm{~cm}^{3}$. The MSR along with other shielding (MIR, reflection and absorption phenomena) mechanisms could be responsible for this interesting observation. Since the EMI SE of the frustum shaped structure at $4 \mathrm{wt} \%$ MWCNT loading is more than $-16 \mathrm{~dB}$ and specific shielding effectiveness is always higher than that of the solid structures, surface architected samples enabled via $3 \mathrm{D}$ printing are considered to be a promising lightweight EMI shielding structure. In some recent studies, researchers incorporated various carbon nanofillers such as graphene, carbon black, and CNT in polymer matrices to study the EMI shielding performance of nanocomposites. Figure 8 compares the EMI SE of our 3D printed PPR/ MWCNT nanocomposites with those of extant work, where EMI shielding test samples were papered by AM techniques. Our results demonstrate that our PPR/MWCNT nanocomposites have superior EMI SE at low filler loading.

\section{Mechanical properties}

In the previous section, we have shown that EMI SE is printing direction-dependent, and our focus was to optimize EMI SE. However, nanocomposites need to be strong. Therefore, it is important to analyze the

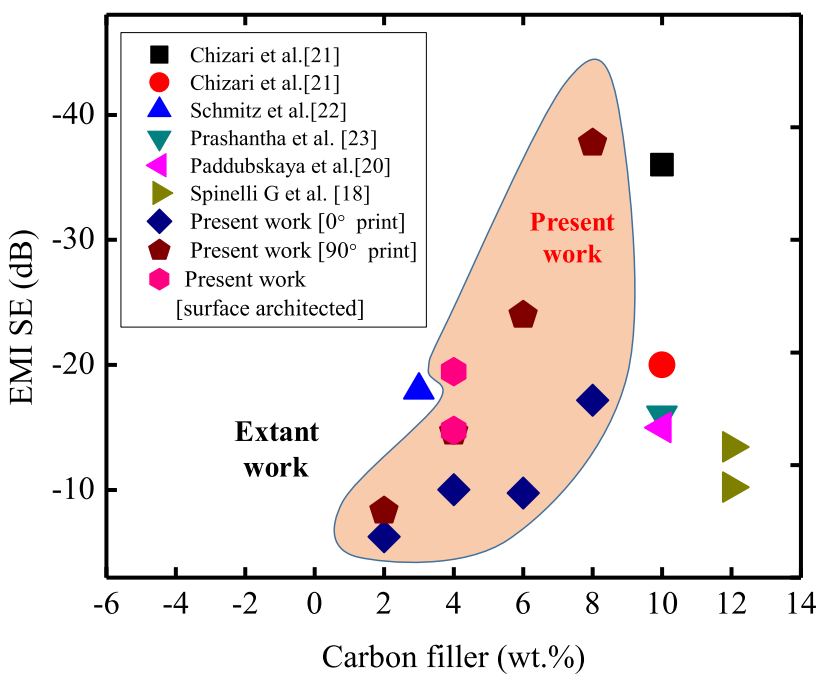

Figure 8 EMI Shielding performance of PPR/MWCNT composites compared with extant work.

mechanical performance of polymer nanocomposites developed for EMI shielding [5, 32, 54-56]. Figure 9a, $\mathrm{b}$ shows the representative stress-strain response of neat PPR and PPR/MWCNT nanocomposites samples from a three-point flexture test. It can be observed that the mechanical properties such as flexural modulus and strength of nanoengineered PPR nanocomposites (printed both in $0^{\circ}$ and $90^{\circ}$ directions) enhanced monotonically with the addition of MWCNT as shown in Fig. 9c, d. The flexural modulus (Fig. 9c) of nanocomposites significantly increases with MWCNT loading $(69 \%$ and $24 \%$ improvement for $8 \mathrm{wt} \%$ MWCNT loading for the samples fabricated in $0^{\circ}$ and $90^{\circ}$ directions, respectively (see Tables 1 and 2)). The improved performance is attributed to the inherent high stiffness of MWCNT and their ability to increase melt crystallization of PPR [57]. The degree of crystallinity of PPR composites increases with MWCNT loading which is confirmed from XRD spectra of composites (Fig S7; Table S2). The addition of MWCNTs restrict the movement of the macromolecular chains of the matrix due to the physical cross-linking between the fillers and the matrix [58]. Interestingly, it is also clear from XRD plot that \%crystallinity of composites is not varying significantly before and after 3D printing (Table S2).

Furthermore, the flexural strength of the nanocomposites depends on the state of filler dispersion and interfacial interaction; an increase in flexural strength can be achieved only with uniform 

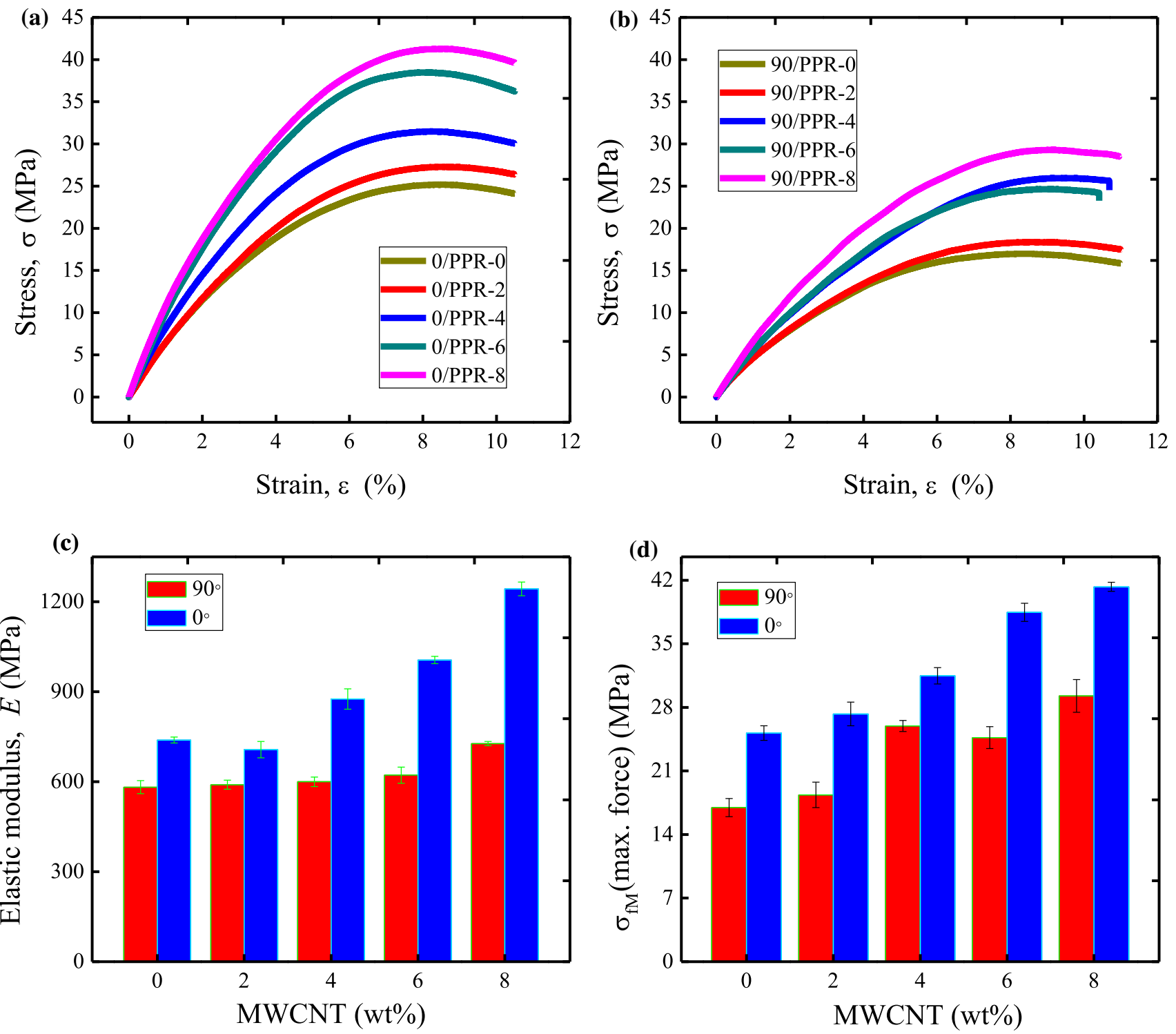

Figure 9 a and $\mathbf{b}$ shows representative stress-strain response of PPR/MWCNT nanocomposites printed in $0^{\circ}$ and $90^{\circ}$ directions from a three-point bending test, while $\mathbf{c}$ and $\mathbf{d}$ shows the of elastic

dispersion. The flexural strength (Fig. 9d) of the $0^{\circ}$ and $90^{\circ} \mathrm{PPR} / \mathrm{MWCNT}$ nanocomposites increased about $\sim 63 \%$ over neat $0 /$ PPR for 0/PPR-8 and $\sim$ $72 \%$ over neat 90/PPR for 90/PPR-8 samples, revealing the effective stress transfer from the PPR matrix to MWCNT. Interestingly, at comparative loadings, the modulus and strength of $0 / P P R$ nanocomposites are found to be higher compared to 90/PPR nanocomposites. The flexural modulus and strength of neat PPR printed in $0^{\circ}$ direction (i.e., $0 /$ PPR-0) showed $21 \%$ and $36 \%$ higher than those of $90^{\circ}$ (90/PPR-0) samples, respectively. This is because,

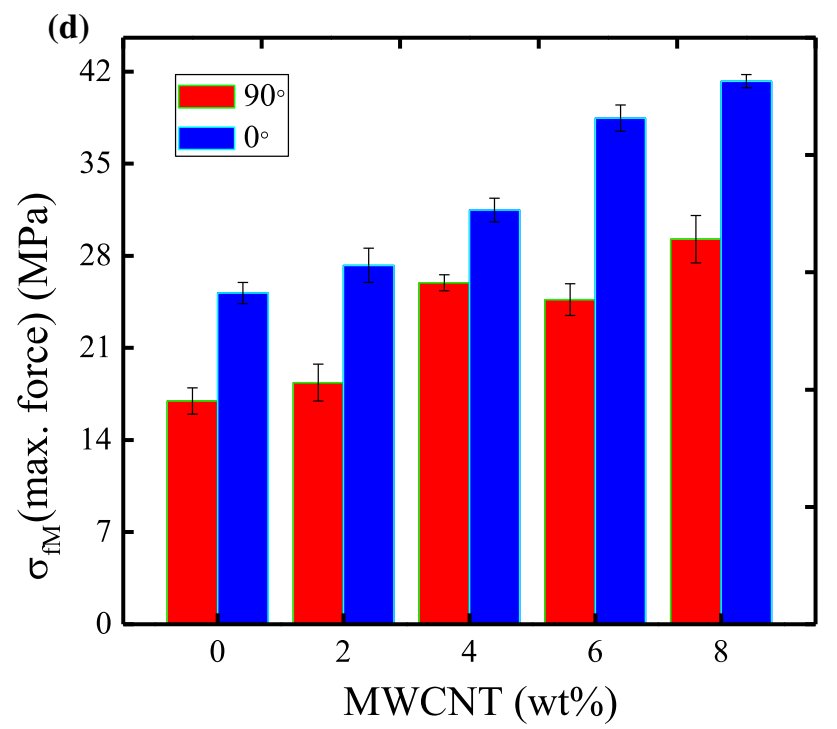

modulus and maximum stress as a function of MWCNT loading of $\mathrm{PPR} / \mathrm{MWCNT}$ nanocomposites printed in $0^{\circ}$ and $90^{\circ}$ directions.

for $0^{\circ}$ orientation, rasters offer more resistance to bending as they are perpendicular to bending plane. When raster orientation changes (from $0^{\circ}$ to $90^{\circ}$ ), their inclination with respect to blending plane changes and produces rasters of smaller length reducing the mechanical properties of nanocomposites. Furthermore, in AM process, the welding of succeeding extruded layer, degree of bonding, the resultant mesostructural features and printing direction dictate the mechanical response $3 \mathrm{D}$ printed samples. The mesostructural features describe the neck growth, forming the discrete bonds and voids 


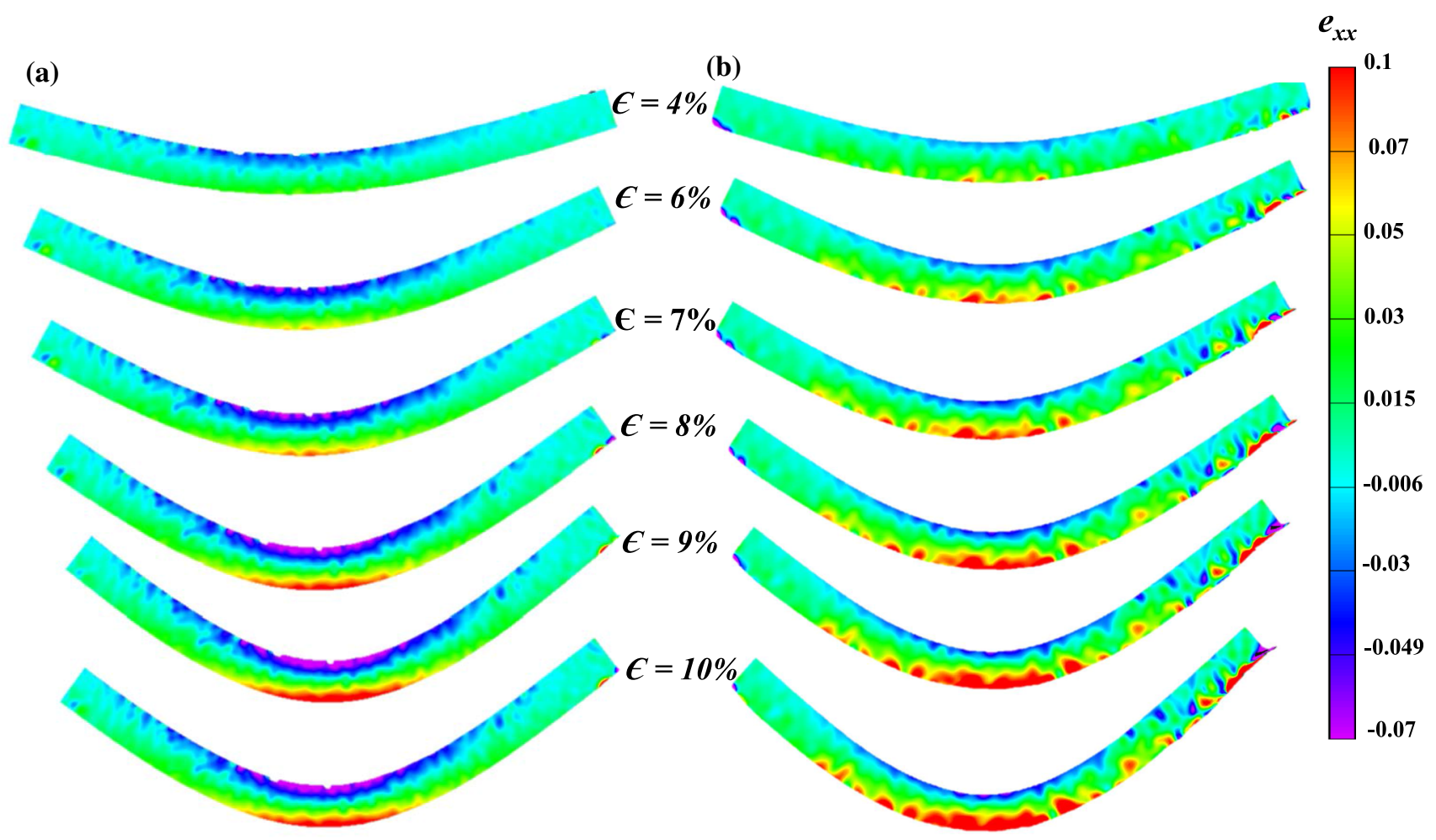

Figure 10 Strain field analysis of $3 \mathrm{D}$ printed samples: a neat PPR samples printed in $0^{\circ}$ direction and $\mathbf{b}$ printed in $90^{\circ}$ direction.

between adjacent layers. Additionally, the anisotropy that stems from the layered structure, raster patterns and printing direction has been observed to impact mechanical properties [52, 54, 59]. The samples printed in $0^{\circ}$ direction displayed excellent mechanical response because each extruded layer (bead) contributes to mechanical performance like a bunch of fibers perpendicular to force indenter. While in $90^{\circ}$ samples, the load is transferred through the interfilament weak link, each extruded layer (beads) responding discretely and hence load is not transferred throughout the sample. This is also confirmed form the DIC images [50] (Fig. 10). These 3D printable nanocomposites with excellent electrical and mechanical properties are considered favorable from the viewpoint of practical applicability, particularly for realizing mechanically stable EMI shielding structures.

\section{Conclusions}

In-house nanoengineered PPR/MWCNT filament feedstocks up to $8 \mathrm{wt} \%$ MWCNT loading were successfully realized through high shear-induced meltblending technique and nanocomposite samples were fabricated via customized FFF AM in two printing directions (i.e., $0^{\circ}$ and $90^{\circ}$ ). The printing direction-dependent multifunctional characteristics such as strength, elastic modulus, AC electrical conductivity and shielding effectiveness were analyzed and probable shielding mechanism was proposed. The obtained results confirmed that shear-induced dispersion of MWCNT imparted electrical percolation and load bearing interfaces to the nanocomposites. The nanocomposites samples displayed satisfactory AC conductivity $\left(\sim 10^{-2} \mathrm{~s} / \mathrm{cm}\right.$ at $8 \mathrm{wt} \%$ MWCNT loading) and improved mechanical properties with an enhancement in elastic modulus of $68 \%$ for $0 /$ PPR- 8 and $\sim 25 \%$ for 90/PPR-8 over neat PPR. Furthermore, the improved electrical properties, shear-induced uniform dispersion of MWCNT and sample printing directions $\left(0^{\circ}\right.$ and $\left.90^{\circ}\right)$ are responsible for observed shielding effectiveness of $-17 \mathrm{~dB}$ ( $\sim 99 \%$ radiation blocking) and $-37 \mathrm{~dB}(\sim 99.99 \%$ radiation blocking) for 0/PPR-8 and 90/PPR-8 nanocomposites, respectively. In addition, it was also realized that samples printed in $90^{\circ}$ direction show better shielding response, whereas $0^{\circ}$ direction samples displayed better mechanical properties for all loadings (2-8 wt\% MWCNT) considered. The defect- 
free printing in $90^{\circ}$ (confirmed via $\mu \mathrm{CT}$ ) is responsible for better EMI shielding properties, whereas the excellent mechanical response in $0^{\circ}$ direction samples is attributed to the orientation of the beads. In $0^{\circ}$ direction samples, each bead behaved like a continuous fiber contributing to mechanical performance, while in $90^{\circ}$ samples, the load was transferred through the inter-bead weak link. The surface architected (frustum) structure showed maximum specific SE value of $\sim-40 \mathrm{~dB} \mathrm{~g}^{-1} \mathrm{~cm}^{3}$ which is $38 \%$ higher than that of the plain sample. The enhanced performance of surface architected sample is attributed to MSR and other SE mechanisms. These 3D printed nanocomposites with improved mechanical performance and electrical conductivity along with excellent shielding effectiveness ( $\sim 99 \%$ attenuation) are considered as a promising candidate for industrially viable microwave shields. The results of this study provide guidelines for the fabrication of efficient lightweight EMI shields for applications such as portable electronic devices and aerospace or spacebased satellite structures.

\section{Acknowledgement}

Authors would like to thanks to Abu Dhabi National Oil Company (ADNOC) for providing the research grant (Award No: EX2016-000010) and Borouge Pte. Ltd, UAE, for providing polypropylene random copolymer and extrusion facilities for the fabrication of filaments.

Supplementary Information: The online version contains supplementary material available at http s://doi.org/10.1007/s10853-021-05985-0.

Open Access This article is licensed under a Creative Commons Attribution 4.0 International License, which permits use, sharing, adaptation, distribution and reproduction in any medium or format, as long as you give appropriate credit to the original author(s) and the source, provide a link to the Creative Commons licence, and indicate if changes were made. The images or other third party material in this article are included in the article's Creative Commons licence, unless indicated otherwise in a credit line to the material. If material is not included in the article's
Creative Commons licence and your intended use is not permitted by statutory regulation or exceeds the permitted use, you will need to obtain permission directly from the copyright holder. To view a copy of this licence, visit http://creativecommons.org/licen ses/by/4.0/.

\section{References}

[1] Abbasi H, Antunes M, Velasco JI (2019) Recent advances in carbon-based polymer nanocomposites for electromagnetic interference shielding. Prog Mater Sci 103:319-373

[2] Choudary V, Dhawan SK, Saini P (2012) Polymer based nanocomposites for electromagnetic interference (EMI) shielding. EMI Shielding Theory and Development of New Materials; Research Signpost, Kerala, pp. 67-100

[3] Colaneri NF, Schacklette LW (1992) EMI shielding measurements of conductive polymer blends. IEEE Trans Instrum Meas 41(2):291-297

[4] Verma P, Saini P, Malik RS, Choudhary V (2015) Excellent electromagnetic interference shielding and mechanical properties of high loading carbon-nanotubes/polymer composites designed using melt recirculation equipped twinscrew extruder. Carbon 89:308-317

[5] Verma P, Saini P, Choudhary V (2015) Designing of carbon nanotube/polymer composites using melt recirculation approach: effect of aspect ratio on mechanical, electrical and EMI shielding response. Mater Des 88:269-277

[6] Al-Saleh MH, Saadeh WH, Sundararaj U (2013) EMI shielding effectiveness of carbon based nanostructured polymeric materials: a comparative study. Carbon 60:146-156

[7] Chung DDL (2000) Materials for electromagnetic interference shielding. J Mater Eng Perform 9(3):350-354

[8] Chung DDL (2001) Electromagnetic interference shielding effectiveness of carbon materials. Carbon 39(2):279-285

[9] Kim HS, Chung KY, Cho BW (2009) Electrochemical properties of carbon-coated $\mathrm{Si} / \mathrm{B}$ composite anode for lithium ion batteries. J Power Sour 189(1):108-113

[10] Luo X, Chung DDL (1996) Electromagnetic interference shielding reaching $130 \mathrm{~dB}$ using flexible graphite. Carbon 34(10):1293-1294

[11] Al-Saleh MH, Sundararaj U (2009) A review of vapor grown carbon nanofiber/polymer conductive composites. Carbon 47(1):2-22

[12] Viskadourakis Z, Vasilopoulos K, Economou E, Soukoulis CM, Kenanakis G (2017) Electromagnetic shielding 
effectiveness of 3D printed polymer composites. Appl Phys A $736: 1-7$

[13] Liljenhjerte J, Upadhyaya P, Kumar S (2016) Hyperelastic strain measurements and constitutive parameters identification of 3D printed soft polymers by image processing. Addit Manuf 11:40-48

[14] Rajkumar AR, Shanmugam K (2018) Additive manufacturing-enabled shape transformations via FFF 4D printing. J Mater Res 33(24):4362-4376

[15] Dugbenoo E, Arif MF, Wardle BL, Kumar S (2018) Enhanced bonding via additive manufacturing-enabled surface tailoring of 3D printed continuous-fiber composites. Adv Eng Mater 20(12):1800691

[16] Khan M, Kumar S (2018) Performance enhancement of tubular multilayers via compliance-tailoring: 3D printing, testing and modeling. Int J Mech Sci 140:93-108

[17] Andrew JJ, Ubaid J, Hafeez F, Schiffer A, Kumar S (2019) Impact performance enhancement of honeycombs through additive manufacturing-enabled geometrical tailoring. IntJImpact Eng 134:103360

[18] Wang X, Jiang M, Zhou Z, Gou J, Hui D (2017) 3D printing of polymer matrix composites: a review and prospective. Compos B Eng 110:442-458

[19] Feng P, Kong Y, Yu L, Li Y, Gao C, Peng S et al (2019) Molybdenum disulfide nanosheets embedded with nanodiamond particles: co-dispersion nanostructures as reinforcements for polymer scaffolds. Appl Mater Today 17:216-226

[20] Andrew JJ, Verma P, Kumar S (2021) Impact behavior of nanoengineered, 3D printed plate-lattices. MaterDes 202:1095

[21] Gupta V, Alam F, Verma P, Kannan A, Kumar S (2021) Additive manufacturing enabled, microarchitected, hierarchically porous polylactic-acid/Lithium iron phosphate/carbon nanotube nanocomposite electrodes for high performance Li-Ion batteries. J Power Sources 494:229625

[22] Farahani RD, Dubé M, Therriault D (2016) Three-dimensional printing of multifunctional nanocomposites: manufacturing techniques and applications. Adv Mater 28(28):5794-5821

[23] Berretta S, Davies R, Shyng YT, Wang Y, Ghita O (2017) Fused deposition modelling of high temperature polymers: exploring CNT PEEK composites. Polym Test 63:251-262

[24] Gnanasekaran K, Heijmans T, van Bennekom S, Woldhuis $\mathrm{H}$, Wijnia S, de With $\mathrm{G}$ et al (2017) 3D printing of CNT-and graphene-based conductive polymer nanocomposites by fused deposition modeling. Appl Mater Today 9:21-28

[25] Arif M, Alhashmi H, Varadarajan K, Koo JH, Hart A, Kumar S (2020) Multifunctional performance of carbon nanotubes and graphene nanoplatelets reinforced PEEK composites enabled via FFF additive manufacturing. ComposPart B Eng 184:107625

[26] Paddubskaya A, Valynets N, Kuzhir P, Batrakov K, Maksimenko S, Kotsilkova R et al (2016) Electromagnetic and thermal properties of three-dimensional printed multilayered nano-carbon/poly (lactic) acid structures. JApplPhys 119(13):135102

[27] Chizari K, Arjmand M, Liu Z, Sundararaj U, Therriault D (2017) Three-dimensional printing of highly conductive polymer nanocomposites for EMI shielding applications. Mater Today Commun 11:112-118

[28] Schmitz D, Ecco L, Dul S, Pereira E, Soares B, Barra G et al (2018) Electromagnetic interference shielding effectiveness of ABS carbon-based composites manufactured via fused deposition modelling. Mater Today Commun 15:70-80

[29] Prashantha K, Roger F (2017) Multifunctional properties of 3D printed poly (lactic acid)/graphene nanocomposites by fused deposition modeling. J Macromol Sci Part A 54(1):24-29

[30] Spinelli G, Lamberti P, Tucci V, Kotsilkova R, Ivanov E, Menseidov D et al (2019) Nanocarbon/poly (lactic) acid for 3d printing: effect of fillers content on electromagnetic and thermal properties. Materials 12(15):2369

[31] Spinelli G, Lamberti P, Tucci V, Kotsilkova R, Tabakova S, Ivanova $\mathrm{R}$ et al (2018) Morphological, rheological and electromagnetic properties of nanocarbon/poly (lactic) acid for $3 \mathrm{~d}$ printing: solution blending versus melt mixing. Materials 11(11):2256

[32] El Achaby M, Qaiss A (2013) Processing and properties of polyethylene reinforced by graphene nanosheets and carbon nanotubes. Mater Des 44:81-89

[33] Mora A, Verma P, Kumar S (2020) Electrical conductivity of $\mathrm{CNT}$ /polymer composites: 3D printing, measurements and modeling. ComposPart B Eng 183:107600

[34] Verma P, Schiffer A, Kumar S (2021) Thermo-resistive and thermo-piezoresistive sensitivity of carbon nanostructure engineered thermoplastic composites processed via additive manufacturing. Polym Test 93:106961

[35] Shah TK, Malecki HC, Basantkumar RR, Liu H, Fleischer CA, Sedlak JJ, et al (2014) Carbon nanostructures and methods of making the same. Google Patents

[36] Arif MF, Kumar S, Gupta TK, Varadarajan KM (2018) Strong linear-piezoresistive-response of carbon nanostructures reinforced hyperelastic polymer nanocomposites. Compos A Appl Sci Manuf 113:141-149

[37] Carneiro OS, Covas JA, Vergnes B (2000) Experimental and theoretical study of twin-screw extrusion of polypropylene. J Appl Polym Sci 78(7):1419-1430

[38] Preetha Nair K, Thomas P, Joseph R (2012) Latex stage blending of multiwalled carbon nanotube in carboxylated 
acrylonitrile butadiene rubber: mechanical and electrical properties. Mater Des 41:23-30

[39] Kum C, Sung Y-T, Han M, Kim W, Lee H, Lee S-J et al (2006) Effects of morphology on the electrical and mechanical properties of the polycarbonate/multi-walled carbon nanotube composites. Macromol Res 14(4):456-460

[40] Chipara DM, Chipara AC, Chipara M (2011) Raman spectroscopy of carbonaceous materials: a concise review-a critical review focused on the Raman spectroscopy of carbonaceous materials and of polymer-based nanocomposites that contain carbonaceous (nano) materials as fillers. Spectroscopy-Eugene 26(10):42

[41] Chipara DM, Macossay J, Ybarra AV, Chipara A, Eubanks TM, Chipara M (2013) Raman spectroscopy of polystyrene nanofibers-multiwalled carbon nanotubes composites. Appl Surf Sci 275:23-27

[42] Bansala T, Joshi M, Mukhopadhyay S, Doong R-A, Chaudhary M (2017) Electrical and dielectric properties of exfoliated thermally reduced graphene based polyurethane nanocomposites. J Nanosci Nanotechnol 17(12):8782-8790

[43] Tjong SC, Liang GD, Bao SP (2007) Electrical behavior of polypropylene/multiwalled carbon nanotube nanocomposites with low percolation threshold. Scr Mater 57(6):461-464

[44] De Vivo B, Lamberti P, Spinelli G, Tucci V (2013) Numerical investigation on the influence factors of the electrical properties of carbon nanotubes-filled composites. J ApplPhys 113(24):24430

[45] Dyre JC, Schrøder TB (2000) Universality of ac conduction in disordered solids. Rev Mod Phys 72(3):873

[46] Joo J, Epstein AJ (1994) Electromagnetic radiation shielding by intrinsically conducting polymers. Appl Phys Lett 65(18):2278-2280

[47] Ott HW (2011) Electromagnetic compatibility engineering. Wiley, New Jersey

[48] Paul CR (2006) Introduction to electromagnetic compatibility. Wiley, New Jersey

[49] Saini P, Choudhary V, Singh B, Mathur R, Dhawan S (2011) Enhanced microwave absorption behavior of polyaniline$\mathrm{CNT}$ /polystyrene blend in 12.4-18.0 GHz range. Synth Metals 161(15):1522-1526
[50] Arif M, Kumar S, Varadarajan K, Cantwell W (2018) Performance of biocompatible PEEK processed by fused deposition additive manufacturing. Mater Des 146:249-259

[51] Odell D, Wright PK, Montero M, Roundy S, Ahn SH (2002) Anisotropic material properties of fused deposition modeling ABS. Rapid Prototyp J 8(4):248-257

[52] Durgun I, Ertan R (2014) Experimental investigation of FDM process for improvement of mechanical properties and production cost. Rapid Prototyp J 20(3):228-235

[53] Ameli A, Nofar M, Wang S, Park CB (2014) Lightweight polypropylene/stainless-steel fiber composite foams with low percolation for efficient electromagnetic interference shielding. ACS Appl Mater Interfaces 6(14):11091-11100

[54] Sood AK, Ohdar RK, Mahapatra SS (2010) Parametric appraisal of mechanical property of fused deposition modelling processed parts. Mater Des 31(1):287-295

[55] Heidary H, Karimi NZ, Minak G (2018) Investigation on delamination and flexural properties in drilling of carbon nanotube/polymer composites. Compos Struct 201:112-120

[56] Verma P, Kumar A, Chauhan SS, Verma M, Malik RS, Choudhary V (2018) Industrially viable technique for the preparation of HDPE/fly ash composites at high loading: thermal, mechanical, and rheological interpretations. JApplPolymSci 135(11):45995

[57] Verma P, Choudhary V (2015) Polypropylene random copolymer/MWCNT nanocomposites: isothermal crystallization kinetics, structural, and morphological interpretations. J Appl Polym Sci. https://doi.org/10.1002/app.41734

[58] Dubnikova I, Kuvardina E, Krasheninnikov V, Lomakin S, Tchmutin I, Kuznetsov S (2010) The effect of multiwalled carbon nanotube dimensions on the morphology, mechanical, and electrical properties of melt mixed polypropylenebased composites. J Appl Polym Sci 117(1):259-272

[59] Tymrak BM, Kreiger M, Pearce JM (2014) Mechanical properties of components fabricated with open-source 3-D printers under realistic environmental conditions. Mater Des 58:242-246

Publisher's Note Springer Nature remains neutral with regard to jurisdictional claims in published maps and institutional affiliations. 